\title{
Proteomic profiling identifies key coactivators utilized by mutant ERa proteins as potential new therapeutic targets
}

\author{
Leah A. Gates ${ }^{1,2} \cdot$ Guowei Gu ${ }^{1,3} \cdot$ Yue Chen ${ }^{4}$ Aarti D. Rohira ${ }^{1} \cdot$ Jonathan T. Lei $\mathbb{D}^{3,5} \cdot$ Ross A. Hamilton ${ }^{1} \cdot$ Yang $\mathrm{Yu}^{1}$. \\ David M. Lonard ${ }^{1}$ - Jin Wang $\mathbb{1}^{1,6,7}$. Shu-Ping Wang ${ }^{8}$ - David G. Edwards ${ }^{3}$. Philip F. Lavere ${ }^{1}$ - Jiangyong Shao ${ }^{1}$.

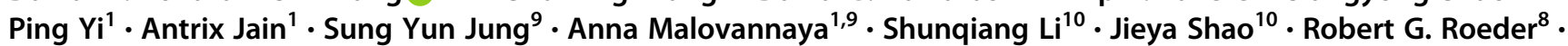 \\ Matthew J. Ellis ${ }^{3,5,11} \cdot$ Jun Qin ${ }^{1,9} \cdot$ Suzanne A. W. Fuqua ${ }^{3,11} \cdot$ Bert W. O'Malley $^{1,11}$ - Charles E. Foulds ${ }^{1,12}$
}

Received: 12 May 2017 / Revised: 2 April 2018 / Accepted: 5 April 2018 / Published online: 11 May 2018

(c) The Author(s) 2018. This article is published with open access

\begin{abstract}
Approximately $75 \%$ of breast cancers are estrogen receptor alpha (ER $\alpha)$-positive and are treatable with endocrine therapies, but often patients develop lethal resistant disease. Frequent mutations (10-40\%) in the ligand-binding domain (LBD) codons in the gene encoding ER $\alpha(E S R I)$ have been identified, resulting in ligand-independent, constitutively active receptors. In addition, ESR1 chromosomal translocations can occur, resulting in fusion proteins that lack the LBD and are entirely unresponsive to all endocrine treatments. Thus, identifying coactivators that bind to these mutant ER $\alpha$ proteins may offer new therapeutic targets for endocrine-resistant cancer. To define coactivator candidate targets, a proteomics approach was performed profiling proteins recruited to the two most common ER $\alpha$ LBD mutants, Y537S and D538G, and an ESR1-YAP1 fusion protein. These mutants displayed enhanced coactivator interactions as compared to unliganded wild-type ER $\alpha$. Inhibition of these coactivators decreased the ability of ESRI mutants to activate transcription and promote breast cancer growth in vitro and in vivo. Thus, we have identified specific coactivators that may be useful as targets for endocrineresistant breast cancers.
\end{abstract}

These authors contributed equally: Leah A. Gates, Guowei Gu.

Electronic supplementary material The online version of this article (https://doi.org/10.1038/s41388-018-0284-2) contains supplementary material, which is available to authorized users.

Charles E. Foulds

foulds@bcm.edu

1 Department of Molecular and Cellular Biology, Baylor College of Medicine, Houston, TX 77030, USA

2 Laboratory of Chromatin Biology and Epigenetics, The Rockefeller University, New York, NY 10065, USA

3 Lester and Sue Smith Breast Center, Baylor College of Medicine, Houston, TX 77030, USA

4 Employee of Adrienne Helis Malvin Medical Research Foundation, New Orleans, LA 70130, USA

5 Interdepartmental Graduate Program in Translational Biology and Molecular Medicine, Baylor College of Medicine, Houston, TX 77030, USA

6 Department of Pharmacology, Baylor College of Medicine, Houston, TX 77030, USA

\section{Introduction}

Approximately $75 \%$ of breast cancers express estrogen receptor alpha $(\mathrm{ER} \alpha)$ and new therapies are needed for the $\sim 50 \%$ of ER-positive tumors that acquire endocrine resistance [1]. Current endocrine therapies include selective ER $\alpha$

7 Center for Drug Discovery, Baylor College of Medicine, Houston, TX 77030, USA

8 Laboratory of Biochemistry and Molecular Biology, The Rockefeller University, New York, NY 10065, USA

9 Verna and Marrs McLean Department of Biochemistry and Molecular Biology, Baylor College of Medicine, Houston, TX 77030, USA

10 Division of Oncology, Department of Internal Medicine, Washington University School of Medicine, Saint Louis, MO 63110, USA

11 Dan L. Duncan Cancer Center, Baylor College of Medicine, Houston, TX 77030, USA

12 Center for Precision Environmental Health, Baylor College of Medicine, Houston, TX 77030, USA 

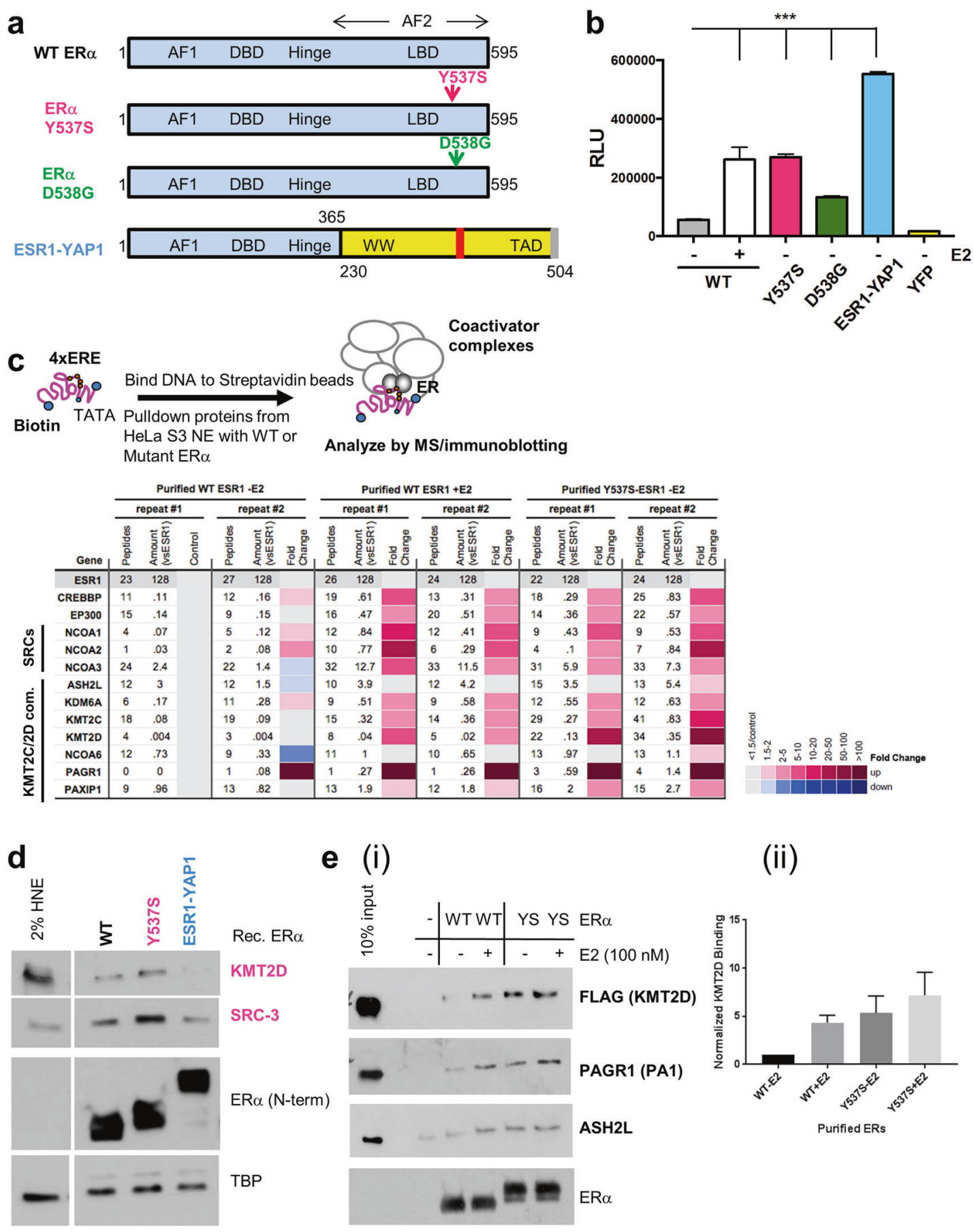

e (i)

(ii)
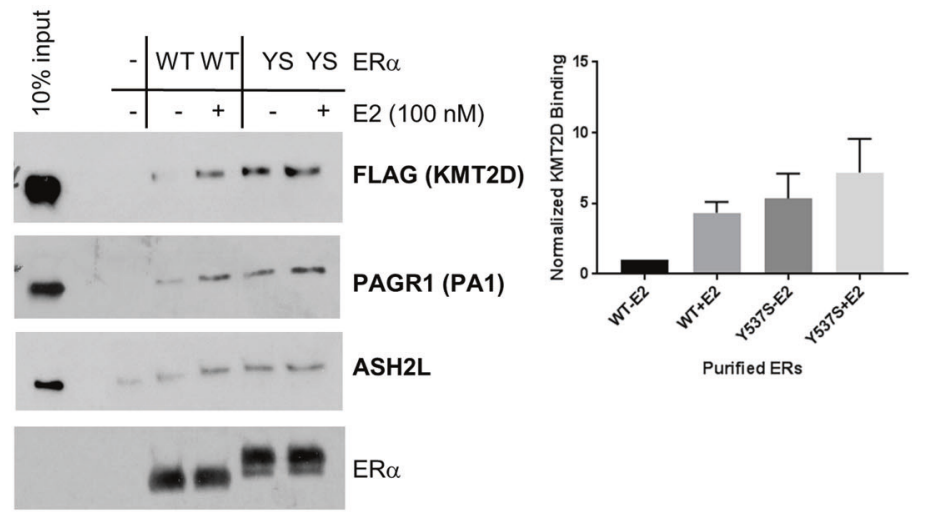

modulators [2], aromatase inhibitors (AIs) [3], and selective $\mathrm{ER} \alpha$ downregulators (SERDs) [4]. ER $\alpha$ plays a major role in the development of therapy-resistant tumors, and its activity is mediated by binding of $17-\beta$ estradiol (E2) to its ligand-binding domain (LBD) for the recruitment of steroid receptor coactivators (SRCs) and other coactivators for transcriptional activation of estrogen response element (ERE)-containing genes [5].

One mechanism for endocrine resistance is thought to be through acquired mutations in ESRl (gene encoding ER $\alpha$ ).
The first ESR1 mutation (Y537N) was identified in a metastatic breast cancer patient and conferred ligandindependent transcriptional activity [6]. Since then, additional LBD point mutations have been identified that are expressed in a subset (10-40\%) of metastatic tumors [714]. ESR I mutations appear to be acquired in response to AI treatment during metastatic progression [15] and are associated with poor survival [15-17]. The Y537S and D538G mutant receptors possess constitutive ERE-driven transcriptional activity [7-11]. These mutations lock helix 12 of 
Fig. 1 Proteomics of co-regulators recruited to the Y537S ER $\alpha$ LBD point mutant. a Schematic diagram of WT, Y537S, and D538G ER $\alpha$ point mutants (mutations indicated by arrows), and the ESR1-YAP1 fusion protein. Numbers refer to amino-acid residues in ER $\alpha$ and YAP1. $A F 1$ activation function 1, DBD DNA-binding domain. Hinge, region between DBD and ligand-binding domain (LBD); $A F 2$ Activation function $2, W W$ WW domain, TAD transcription activation domain. In ESR1-YAP1, blue represents ER $\alpha$ residues (1-365); yellow indicates YAP1 residues (230-504). b Mutant ER $\alpha$ proteins display E2-independent transcriptional activity. Vectors expressing YFP or YFP-tagged WT, Y537S, D538G, or ESR1-YAP1 proteins were coexpressed with an ERE-dependent luciferase reporter (pERE-E1b-luc) in HeLa cells grown in charcoal-stripped fetal bovine serum (FBS). Cells were then treated with/without $10 \mathrm{nM}$ E2 for overnight. Luciferase activity ( $R L U$ relative light units) was assayed from whole-cell extracts of the cells transfected in triplicate. Data are represented as mean $\pm \operatorname{SEM}(n=3) ; * * *<0.001$. c MS data depicted as a heatmap for WT or Y537S ER $\alpha$-dependent coactivators recruited to EREs. (Top) Schematic of ERE DNA pulldown assay using HeLa S3 NE as the source of co-regulators (modified from ref. [21]) and purified ER $\alpha$ proteins. (Bottom) MS data were analyzed from duplicate reactions using a label-free method and depicted as in ref. [21]. Peptides number of peptides detected; amount (vsESR1) amount normalized by sum of area under the curve for six N-terminal ESR1 peptides (see Supplementary Table 2). Fold change represents the ratio of amount detected normalized to unliganded WT ER $\alpha$. Fold change cutoff used was $\geq 1.5$. SRC-1 to -3 (gene symbols: NCOA1, NCOA2, NCOA3), p300 (gene symbol: EP300), CBP (gene symbol: CREBBP). d Immunoblotting validation of KMT2D and SRC-3 enrichment with purified Y537S $\mathrm{ER} \alpha$ bound to EREs using independent DNA pulldown samples in the absence of E2. ER $\alpha$ protein binding was assayed by an $\mathrm{N}$-terminal $(\mathrm{N}$ term) antibody. TBP serves as a loading control. $2 \%$ input represents $2 \%$ of the starting HNE employed in the ERE DNA pulldown. e Y537S ER $\alpha$ and the KMT2D complex interact directly in an enhanced manner relative to unliganded WT ER $\alpha$. ERE DNA pulldown assays were performed with purified ER $\alpha$ proteins and a purified KMT2D "fusion" complex [22], and then analyzed by immunoblotting. (i) Representative immunoblot probing for select KMT2D complex members and ER $\alpha$. (ii) Quantification of KMT2D signal across three independent pulldown assays. Binding was quantified using Image $\mathbf{J}$ and normalized to ER $\alpha$ signal

the $\mathrm{ER} \alpha \mathrm{LBD}$ into an agonist-type conformation [7, 9, 18] and have higher affinities for the SRC-3 coactivator compared to unliganded wild-type (WT) ER $\alpha[14,19]$.

ESR1 chromosomal translocation events also occur in endocrine-resistant, metastatic breast cancer patients resulting in fusion proteins possessing the $\mathrm{N}$ terminus and DNA-binding domain (DBD) of ER $\alpha$, but containing partners from various genes that replace the LBD $[11,20]$. One such fusion, ESR1-YAP1, induced expression of EREcontaining target genes in a ligand-independent manner, and cannot be targeted with standard endocrine therapies since it lacks a LBD [11].

Understanding how ER $\alpha$ mutant proteins function is essential for the development of new therapeutics to treat endocrine-resistant tumors. To define co-regulators binding mutant ER $\alpha$ proteins as potential new targets, we profiled their recruitment to Y537S ER $\alpha$, D538G ER $\alpha$, and ESR1YAP1 proteins bound to EREs using mass spectrometry (MS). We show that inhibition of the most-enhanced binding coactivators reduced ERE-driven transcription and ESR1 mutant expressing breast cancer cell growth.

\section{RESULTS}

\section{Identification of co-regulators recruited to ERa mutants}

Since Y537S, D538G, and ESR1-YAP1 ER $\alpha$ (Fig. 1a) promote E2-independent transcriptional activation of an ERE-dependent reporter (Fig. 1b), we tested whether this activation is through recruiting or repelling distinct coregulators (coactivators and co-repressors). Using our 4xERE DNA pulldown assay to identify co-regulators recruited to ER $\alpha$ [21], we first utilized recombinant WT and Y537S ER $\alpha$, along with HeLa S3 nuclear extract (HNE) to form complexes. Washed complexes were then subjected to label-free, quantitative MS and bound proteins were normalized by the amount of ESR $1 \mathrm{~N}$-terminal peptides bound (Fig. 1c, top; Supplementary Table 2).

Compared with unliganded WT ER $\alpha$, a subset of coactivators were recruited in an enhanced manner to Y537S ER $\alpha$ (Fig. 1c, bottom). Namely, the histone H3 lysine 4 (H3K4) methyltransferase KMT2D complex displayed the greatest enrichment with Y537S ER $\alpha$, along with SRC-1, -2 , and -3 , p300, CBP, and KMT2D's paralog, KMT2C. Immunoblotting validated the enhanced KMT2D and SRC3 recruitment (Fig. 1d).

As SRC-3 directly binds Y537S ER $\alpha$ [14, 19], we tested whether a KMT2D complex [22] would directly interact with Y537S ER $\alpha$. Indeed, the binding of the KMT2D complex was enhanced with Y537S, along with E2-bound WT, compared to unliganded WT ER $\alpha$ (Fig. 1e). We found other potential coactivators with enhanced binding to Y537S ER $\alpha$ (Supplementary Figure 1a). We further validated PELP1 recruitment by immunoblotting, as an inhibitor disrupting this interaction is described [23] (Supplementary Figure 1b). We found very few corepressors had reduced recruitment to Y537S ER $\alpha$ (Supplementary Figure 1c).

As purified D538G ER $\alpha$ failed to recruit SRC-3 despite binding EREs (data not shown), we resorted to using extracts from transfected 293T cells as sources of WT, Y537S, and D538G ER $\alpha$ proteins. We again observed enhanced recruitment of KMT2D and SRCs to Y537S compared to unliganded WT ER $\alpha$ (Supplementary Figure 2). The D538G mutant also recruited these coactivators, but three to four times less than that of Y537S. Additional potential co-regulators displayed enhanced binding to both $\mathrm{ER} \alpha$ mutants. However, for subsequent functional characterization, we chose to focus on SRCs and the KMT2D complex. 


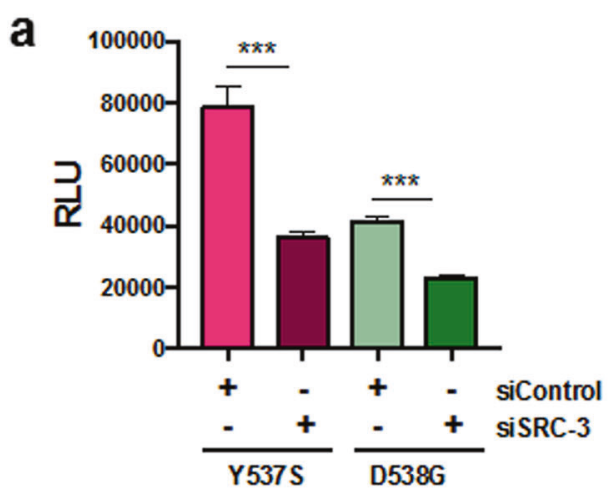

b
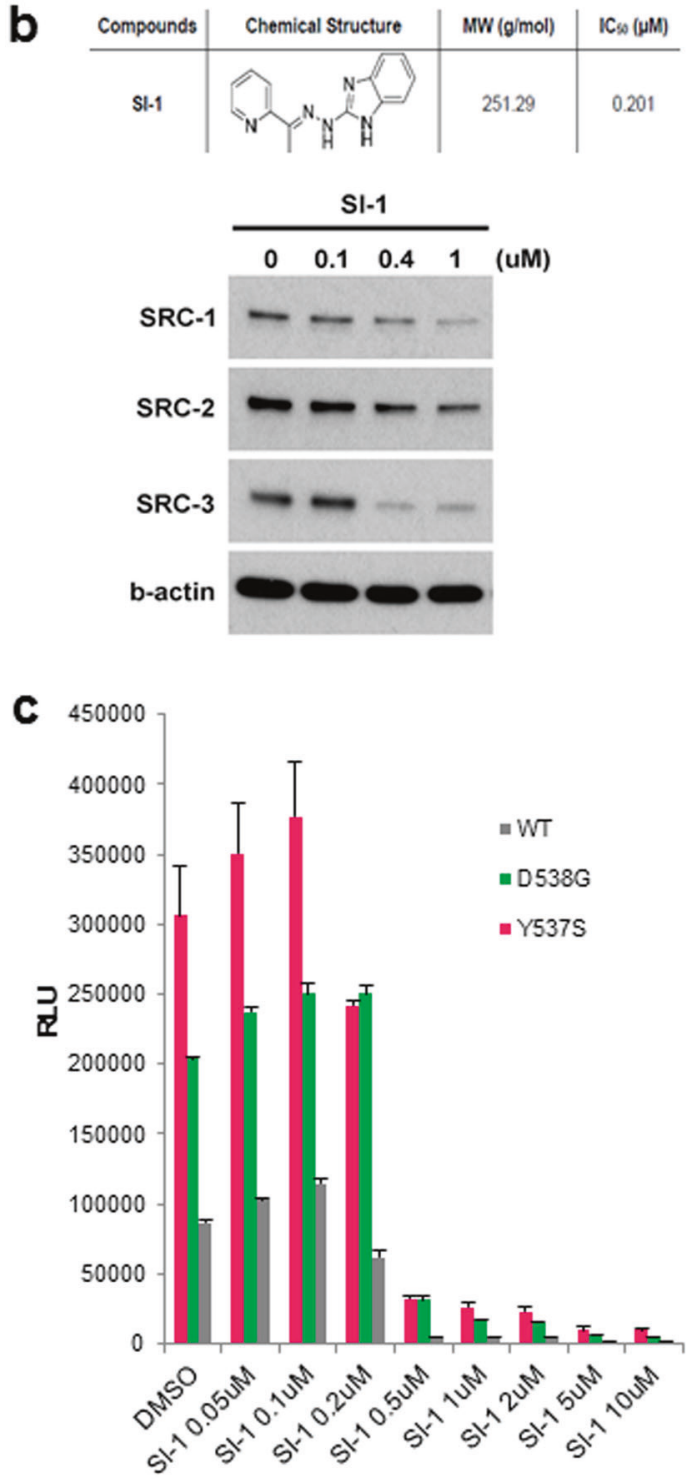

d

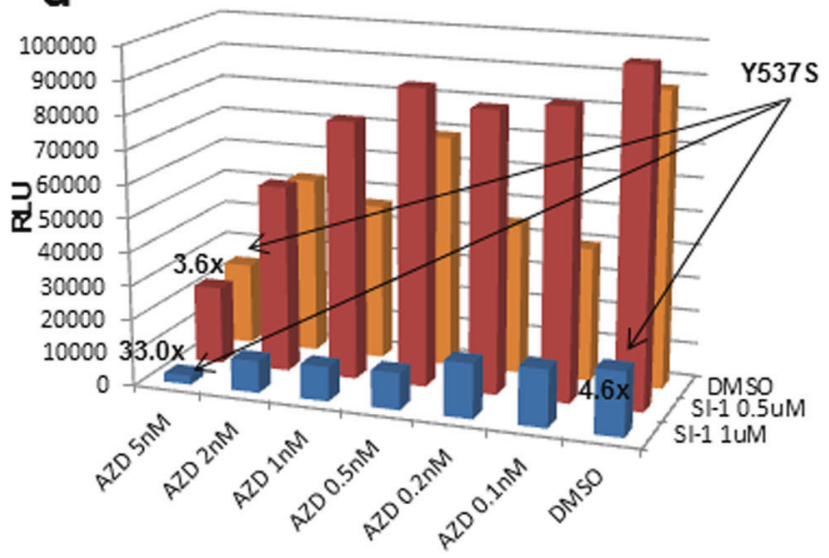

e

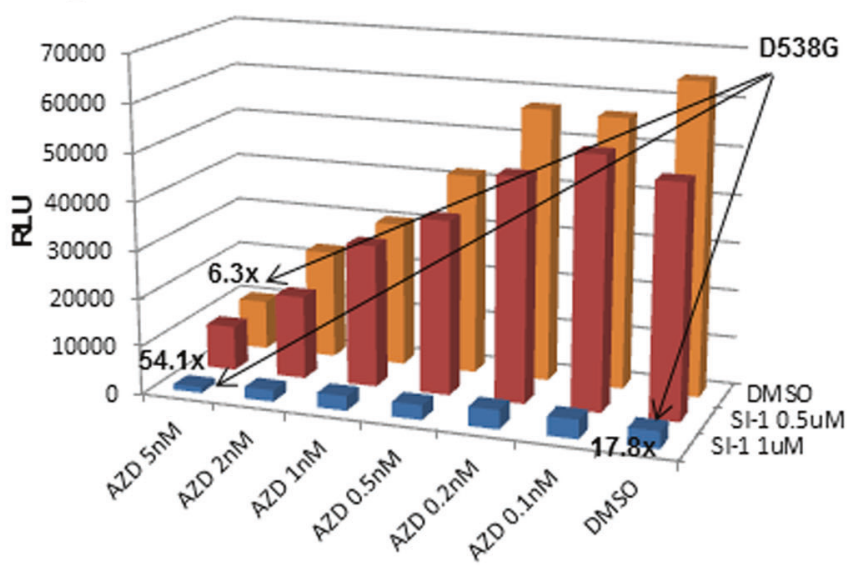

f

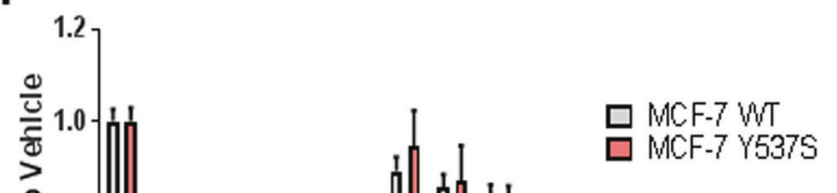

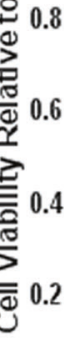

0.0

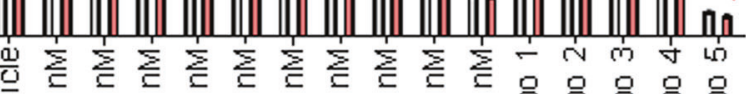

至

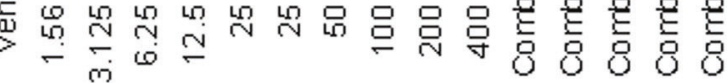


Fig. 2 SRCs are key co-regulators of WT, Y537S, and D538G ER $\alpha$ transcriptional activity and are essential for breast cancer cell growth. a Knockdown of SRC-3 by co-transfection of HeLa cells with an siRNA targeting pool reduced transcriptional activity of LBD point mutant $\mathrm{ER} \alpha$ proteins, as assayed by an ERE-luciferase reporter, in hormonedepleted media. Data are represented as mean $\pm \operatorname{SEM}(n=3) ; * * * p<$ 0.001. RLU relative light units. b A "pan-SRC" inhibitor, SI-1, reduced all three SRC protein levels in MCF-7 breast cancer cells treated overnight, as assayed by immunoblotting. $\beta$-actin serves as a loading control. c SRC inhibitor SI-1 reduced WT, Y537S, and D538G ER $\alpha$ transcriptional activity at concentrations higher than the established $\mathrm{IC}_{50}$. Vectors expressing YFP-tagged WT, Y537S, and D538G ER $\alpha$ proteins were co-expressed with pERE-E1b-luc in HeLa cells, and then cells were treated with dimethyl sulphoxide (DMSO, vehicle control) or SI-1 overnight. Luciferase activity was measured as in Fig. 1b. Data are represented as mean $\pm \operatorname{SEM}(n=3)$. d,e Combination of an SRC inhibitor (SI-1) and an oral SERD (AZD9496) synergistically reduce Y537S (d) and D538G (e) mutant ER $\alpha$ transcriptional activity. Experiment was done as in (c), except that AZD9496 was added with or without SI-1 to co-transfected HeLa cells. Data are represented as mean $(n=3)$. f The oral SERD AZD9496 is more effective than the SRC inhibitor SI-1 in reducing cell viability of MCF-7 lines expressing WT or Y537S ER $\alpha$. The lentiviral transduced MCF-7 stably expressing cell lines were treated with vehicle (DMSO) or different concentrations of AZD9496 or SI-1 as indicated. After 6 days of treatment, viability was assayed by a MTT assay. Data are represented as mean $\pm \operatorname{SEM}(n=3)$. Synergism was observed with combination (Combo) treatments 4 and $5(12.5 /$ $200 \mathrm{nM}$ AZD9496/SI-1; 25/400 nM AZD9496/SI-1) in Y537S ER $\alpha$ -

\section{SRCs are critical for ERa LBD mutant activity and cell growth}

We next tested the functional consequence of enhanced SRC-ER $\alpha$ mutant interactions on transcription. Knockdown of SRC-3 using published siRNAs [24] significantly reduced both Y537S and D538G ER $\alpha$-mediated transcriptional activity on the ERE-Luc reporter (Fig. 2a). Treatment with a small molecule inhibitor (SMI), SI-1, which inhibits the activities of all three SRCs $\left(\mathrm{IC}_{50}=0.2 \mu \mathrm{M}\right)$ [25] and reduces SRC protein levels (Fig. $2 b$ ), severely reduced the transcriptional activities of WT and mutant ER $\alpha$ (Fig. 2c). Cell viability was minimally affected (Supplementary Figure $3 \mathrm{a}$ ). We also tested whether the combination of an oral SERD and SI-1 would further reduce LBD mutant ER $\alpha$ transcriptional activity. We focused on AZD9496 [26] (AZD) as it: (1) reduced endogenous $\mathrm{ER} \alpha$ protein, (2) was significantly more potent than ICI182,780 (ICI, fulvestrant) in reducing mutant $\mathrm{ER} \alpha$ transcriptional activities (unlike another SERD GDC-0810 [27] (GDC; Supplementary Figure 3b-d), and (3) AZD was reported as more effective than ICI at inhibiting tumor growth promoted by Y537S ER $\alpha$ [14]. The combination of SI-1 and AZD synergistically reduced both Y537S and D538G activities on the ERE-luciferase (Luc) reporter (Fig. 2d, e, Supplementary Table 4).
We tested whether SRC inhibition would affect growth of stably expressing WT or Y537S ER $\alpha$ MCF-7 cell lines [28]. SI-1 at $400 \mathrm{nM}$ reduced viability in both WT and Y537S ER $\alpha$-expressing cells by $91 \%$ (Fig. 2f). When combinations of SI-1 with AZD or ICI were tested, a synergistic reduction in viability of Y537S ER $\alpha$-expressing cells was found at the two highest combined doses or highest combined dose, respectively (Fig. $2 \mathrm{f}$ and Supplementary Figure 3e; Supplementary Tables 5 and 6). Thus, SI-1 combined with AZD was most effective in reducing both transcription and cell growth mediated by mutant ER $\alpha$ proteins.

\section{Inhibiting SRCs and mutant ERa most effectively reduces patient-derived xenograft tumor growth}

We next tested the efficacy of an improved pan-SRC inhibitor (SI-2) [25], AZD, or the combination in a patient-derived xenograft (PDX) expressing Y537S $\mathrm{ER} \alpha$ (WHIM 20 [11]) for tumor reduction (Fig. 3a). SI-2 was chosen instead of SI-1, given its reduced IC $_{50}(3.4 \mathrm{nM})$ and ability to reduce $\mathrm{ER}^{-}$tumor growth [25]. After tumors grew to $350 \mathrm{~mm}^{3}$, mice were randomized, E2 was withdrawn to mimic $\mathrm{AI}$ treatment, and mice were then treated with control vehicle, SI-2, AZD, or the combination. After 4.5 weeks, SI- 2 alone significantly reduced tumor volume, AZD gave a larger reduction, but the combination gave the most significant reduction in tumor growth.

We next confirmed that the drugs indeed affected their intended targets and tested for effects on apoptosis and proliferation. First, as expected, AZD treatment significantly reduced $\mathrm{ER} \alpha$ expression in tumor lysates. Unexpectedly, AZD treatment upregulated SRC expression (Fig. 3b, Supplementary Figure 4a), which may have relevance for patients receiving AZD monotherapy in clinical trials (NCT02248090/NCT03236974). Second, we tested the expression of a classical ER target gene, PR (Fig. 3c, Supplementary Figure 4a). While SI-2 did not affect PR expression, AZD clearly did. Third, we found that SI-2 increased an apoptosis marker (cleaved PARP protein), while AZD decreased proliferation as measured by BrdU incorporation (Fig. 3d, e, Supplementary Figure $4 b$ ). Finally, we did not observe any significant toxicity with any drug treatment after examining recipient mouse livers by histochemistry and measuring body weights (Supplementary Figures $4 c-d$ ). Thus, our PDX data support a potential new treatment regime for breast cancers bearing ESR1 LBD mutations, which is to combine a SRC inhibitor with an oral SERD. 


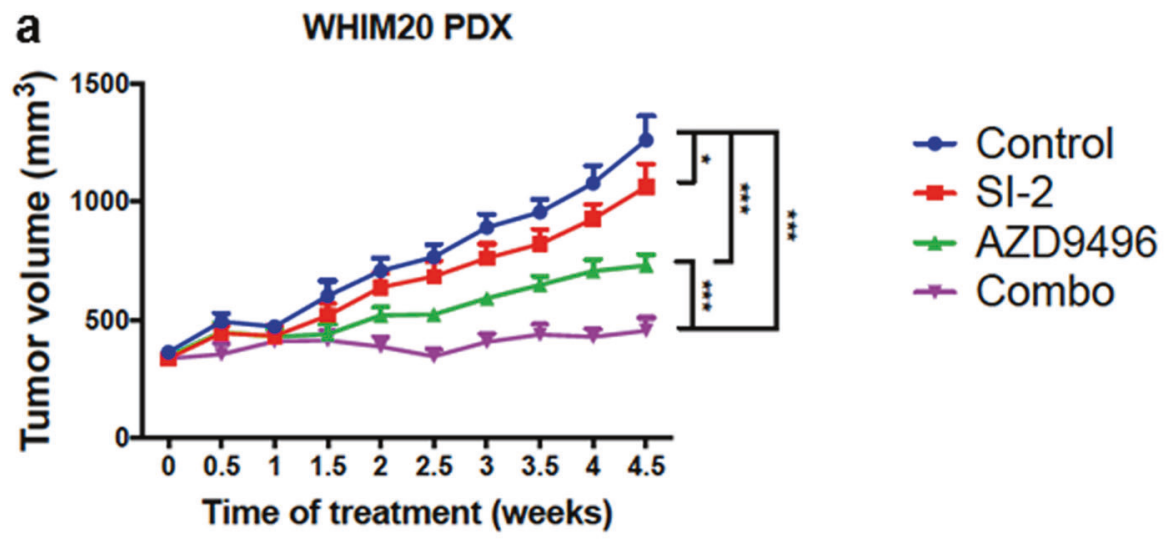

b

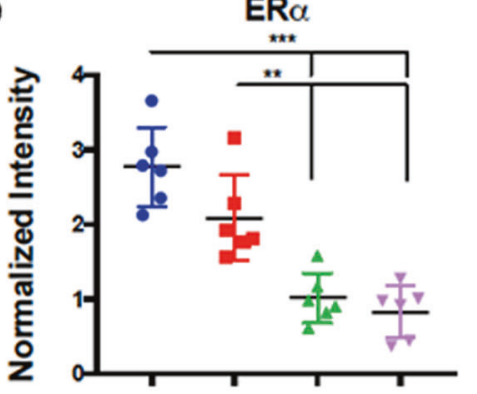

C

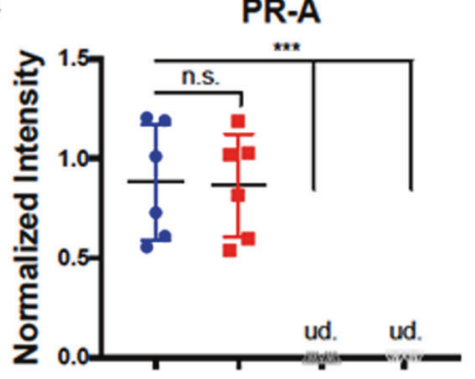

d

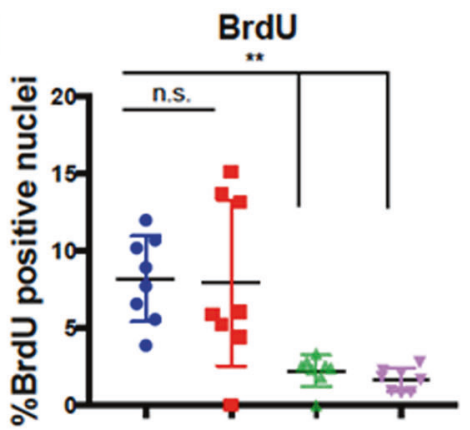

SRC-1

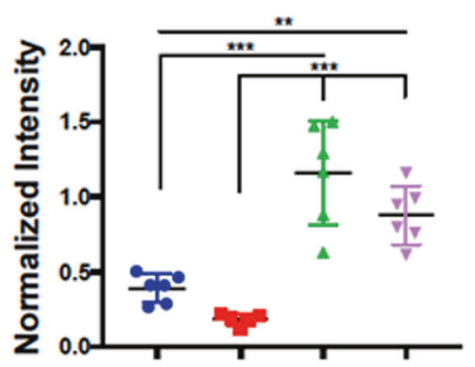

PR-B

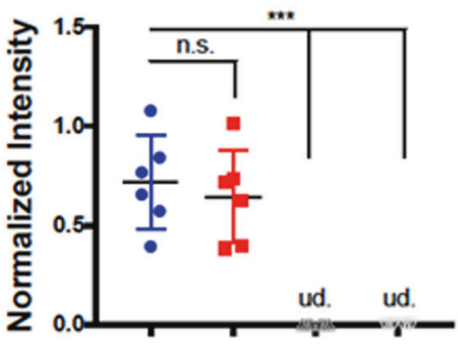

e Cleaved PARP

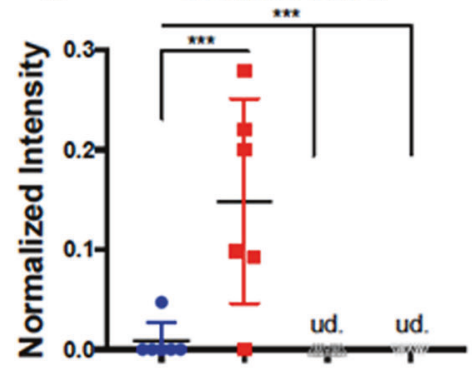

Fig. 3 Inhibition of SRCs and ER $\alpha$ reduces tumor burden in a PDX model of Y537S ER $\alpha$ breast cancer. Significance was determined using one-way ANOVA and Tukey's test to correct for multiple comparisons. $* p<0.05 ; * * p<0.01 ; * * * p<0.001$. a Tumor volume $(n$ $=8$ ) is reduced with treatment of either SI-2 or AZD9496, and further reduced upon treatment with a combination of both inhibitors. Data are represented as mean \pm SEM. b-e Quantification of tumor immunoblotting ( $n=6 /$ treatment) performed with Image $\mathrm{J}$ analysis relative to GAPDH expression or imaging data $(n=8)$ unless otherwise indicated. Data are represented as mean \pm SD. $u d$ undetected. Color legend is the same as in (a). b Quantification of ER $\alpha$, SRC-1, and SRC-3 protein expression across tumors. By Dixon's $Q$ test, the tumor samples in the last lane probed for SRC-1 and SRC-3 (Supplementary Figure 4a) were outliers at $99 \%$ confidence and thus excluded from the Image $\mathrm{J}$ analysis. c The $\mathrm{ER} \alpha$ target gene PR displays reduced expression with AZD9496 and combination treatment. d BrdU is decreased in the AZD9496 and combination therapy groups $(n=8$ mice per group, with mean \pm SD of three slides for each mouse counted). e Cleaved PARP is increased with SI-1 treatment and decreased with AZD9496 and combination therapies 


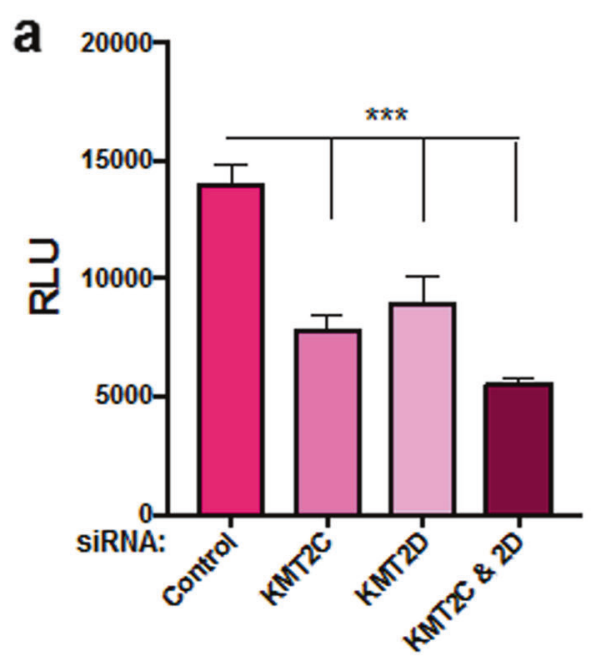

b
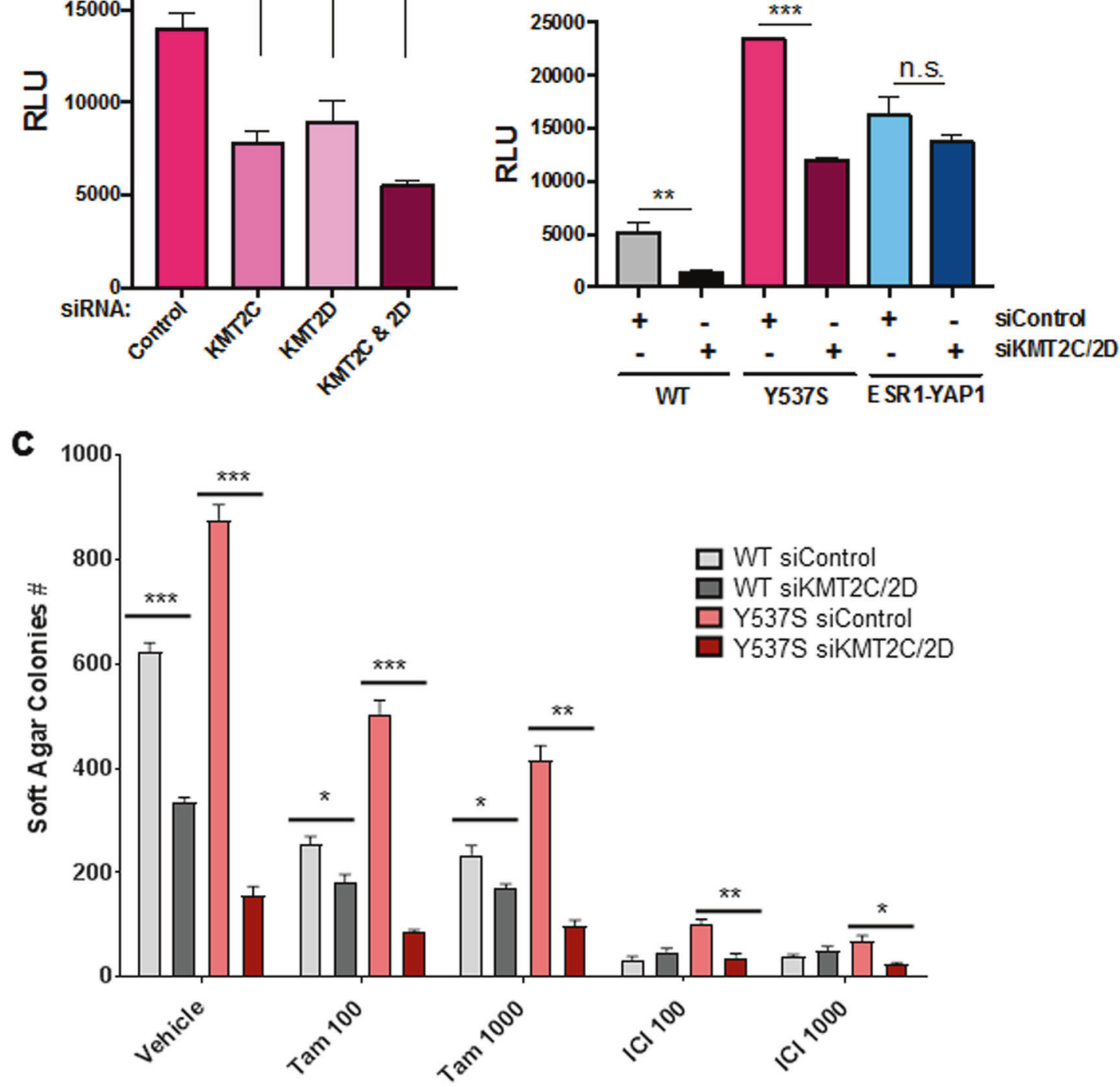

Fig. 4 Knockdown of KMT2C/2D reduces WT and Y537S ER $\alpha$ transcriptional activity and breast cancer cell growth. a HeLa cells grown in phenol red-free, charcoal-stripped media were co-transfected with pERE-E1b-luc, YFP-tagged Y537S ER $\alpha$, and different siRNAs ( $25 \mathrm{nM}$ each for $50 \mathrm{nM}$ total). Cell lysates were assayed for luciferase activity (RLU). Data are represented as mean $\pm \operatorname{SEM}(n=3) ; * * * p<$ 0.001 . NC\#1 siRNA served as the negative control for KMT2D targeting siRNA, while Control-A siRNA pool served as the negative control for KMT2C targeting siRNA pool. b Transfection of siRNAs targeting KMT2C and KMT2D reduced expression of the pERE-E1bluc reporter, as compared to non-targeting siRNAs (siControl), in HeLa cells co-transfected with YFP-tagged WT or Y537S ER $\alpha$

\section{KMT2C/2D are novel coactivators for Y537S ERa}

From above, we found that the KMT2C/2D complexes were preferentially enriched with Y537S ER $\alpha$ (Fig. 1c, Supplementary Figure 2a). To determine the functional role of KMT2C/2D, we tested whether their depletion would affect vectors, but not an YFP-tagged ESR1-YAP1 fusion. Luciferase activity was measured as in Fig. 1b. Data are represented as mean \pm $\operatorname{SEM}(n=3) ; * * p<0.01 ; * * * p<0.001$. c Knockdown of KMT2C and KMT2D in lentiviral transduced stably expressing WT or Y537S MCF-7 cells results in reduced anchorage-independent growth in soft agar and confers sensitivity to anti-estrogens. siRNAs (same as above) were transfected into the two cell lines at a final concentration of $100 \mathrm{nM}(50 \mathrm{nM}$ each), and then re-plated in 24 well plates $24 \mathrm{~h}$ later. After 1 week with either vehicle or anti-estrogen (100 or $1000 \mathrm{nM} 4$ hydroxytamoxifen (Tam) or ICI) treatment, colonies formed in soft agar were counted and quantified. Data are represented as mean \pm SEM $(n=4) ; * p<0.05 ; * * p<0.01 ; * * * p<0.001$

Y537S ER $\alpha$-mediated reporter expression. Knocking down KMT2C, KMT2D, or both together reduced Y537S ER $\alpha$ transcriptional activity (Fig. 4a). Upon double KMT2C/2D knockdown, WT ER $\alpha$ transcriptional activity was also reduced (Fig. 4b). However, ESR1-YAP1 transcriptional 
a

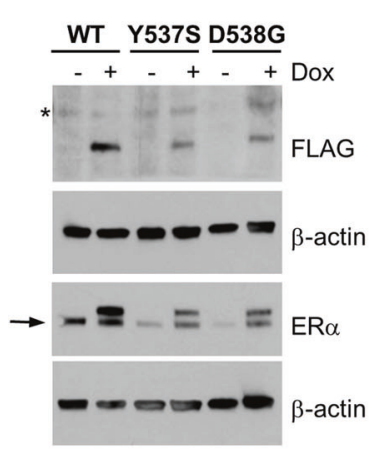

b

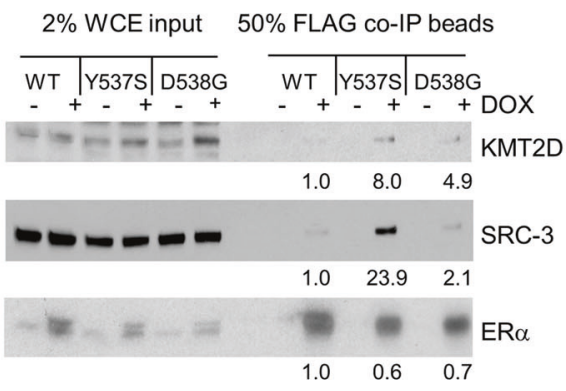

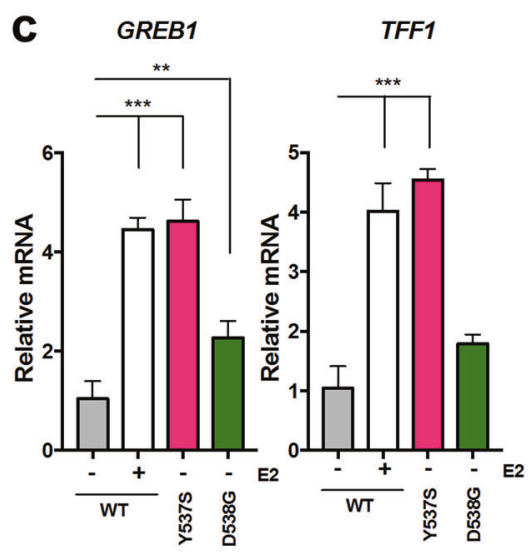

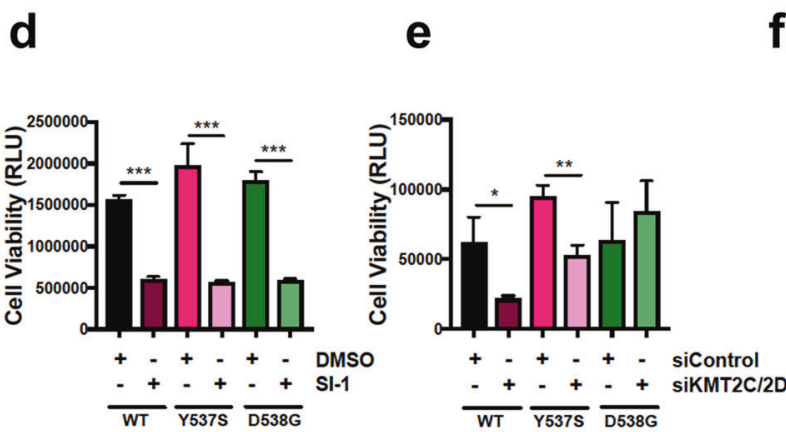

f

GREB1

TFF1

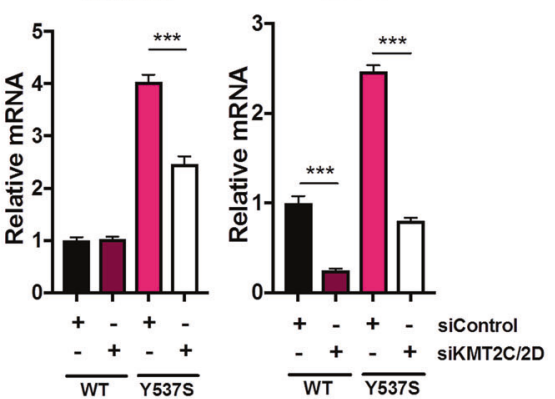

g
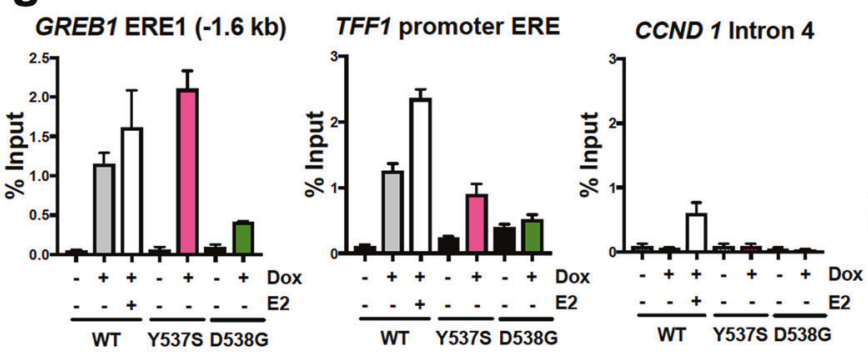

h
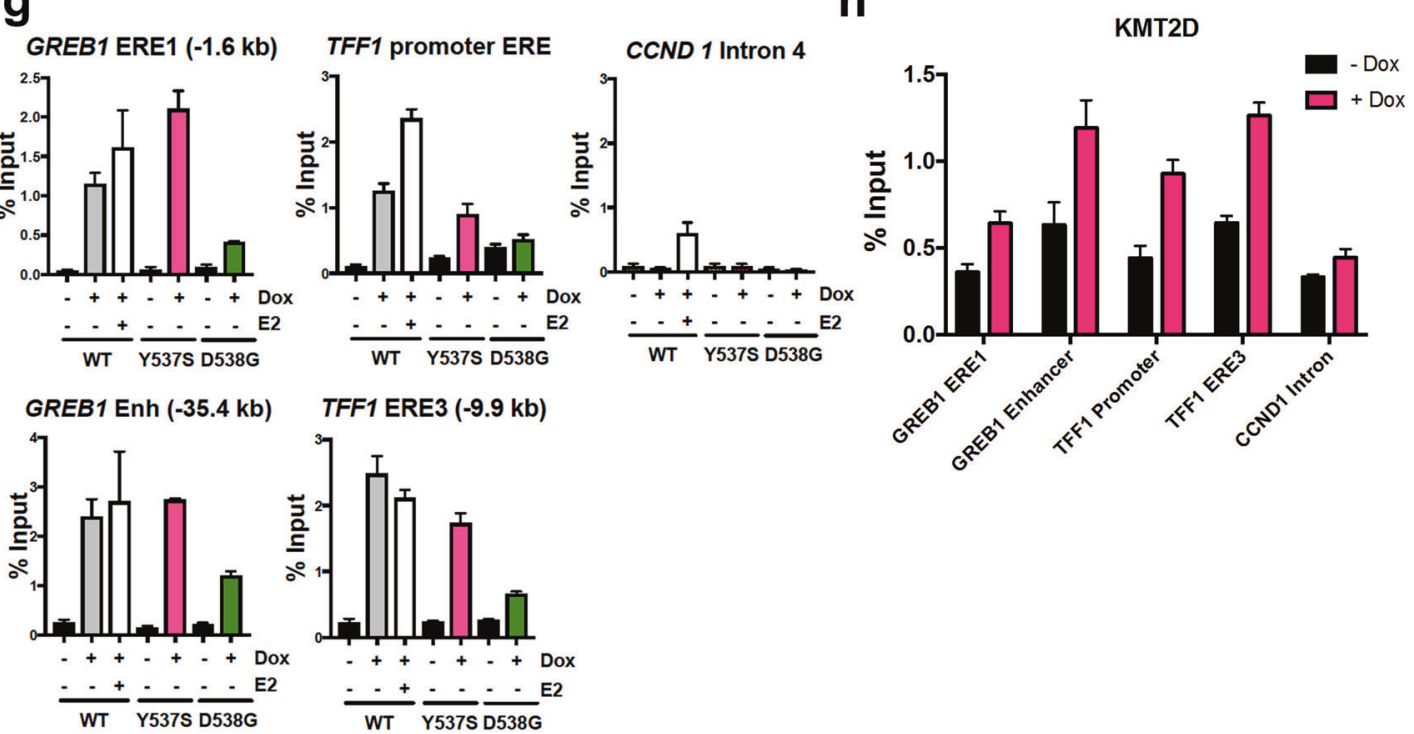

activity was not affected, ruling out a general transcriptional effect.

We additionally found that KMT2C/2D knockdown reduced anchorage-independent growth of WT, Y537S, and D538G ER $\alpha$-expressing cells (Supplementary Figure 5), with significant differences observed between WT and mutant ER $\alpha$ data. More importantly, knockdown of KMT2C/2D significantly sensitized the partially resistant Y537S ER $\alpha$ cells to anti-estrogens currently given in the clinic (Fig. 4c). Overall, our data reveal an important functional role for KMT2C/2D with Y537S ER $\alpha$ in transcription and cell growth.

\section{SRCs and KMT2D are crucial for growth of inducible LBD mutant ERa cells}

As our above cell lines stably overexpressed LBD ER $\alpha$ mutants [28], we created MCF-7 cell lines supporting 
Fig. 5 SRCs and KMT2C/2D promote cell growth and transcription of ERE-containing target genes in conditionally expressed (Dox-inducible) WT and mutant ER $\alpha$ MCF-7 cell lines. Prior to all assays, cell lines were grown in charcoal-stripped, phenol red-free media with/ without Dox for at least 2 days. a Confirmation of FLAG-tagged WT, Y537S, and D538G ER $\alpha$ Dox-inducible expression in MCF-7 cells transduced with specific lentiviruses. Immunoblotting was performed on whole-cell extracts with FLAG, ER $\alpha$ (HC-20 antibody), or $\beta$-actin (loading control) antibodies. *, Nonspecific band. $\rightarrow$, Position of endogenous ER $\alpha$. b KMT2D and SRC-3 co-immunoprecipitate with mutant ER $\alpha$. Whole-cell extracts from Dox-inducible MCF-7 cells were subject to immunoprecipitation of FLAG, followed by immunoblotting. For analysis, intensities were normalized for different precipitated ER $\alpha$ levels by Image J. c Dox-inducible expression of Y537S and D538G ER $\alpha$ in MCF-7 cells results in activation of two canonical ER $\alpha$ target genes independent of E2. Cell lines were treated with Dox and the WT ER $\alpha$ line was treated $( \pm) 10 \mathrm{nM}$ E2 overnight, followed by RNA isolation. Relative levels of GREB1 or TFF1 mRNAs were determined by RT-qPCR with ESR1 mRNA as the normalizer. Data are represented as mean $\pm \operatorname{SEM}(n=3) ; * * p<0.01$; $* * * p<0.001$. d, e Cell viability (measured by Cell Titer Glo as RLU) of Dox-inducible WT, Y537S, and D538G ER $\alpha$ expressing MCF-7 lines (induced as above). ${ }^{*} p<0.05 ; * * p<0.01 ; * * *<0.001$. d Cell viability is reduced in all three cell lines upon treatment with SRC inhibitor SI-1 $(1 \mu \mathrm{M})$ after 3 days' exposure. DMSO served as the vehicle control. Data are represented as mean $\pm \operatorname{SEM}(n=3)$. e Cell viability of Dox-inducible WT and Y537S ER $\alpha$-expressing MCF-7 lines, but not the D538G-expressing $\mathrm{ER} \alpha$ line, is reduced upon knockdown of KMT2C and KMT2D after 3 days exposure to $100 \mathrm{nM}$ total siRNA $(50 \mathrm{nM}$ each). Data are represented as mean $\pm \mathrm{SEM}(n=$ 3). f Knockdown of KMT2C and KMT2D reduces Y537S ER $\alpha$ enhanced expression of GREB1 and TFF1. Cells were transfected with siRNAs (100 nM total, $50 \mathrm{nM}$ each). Relative levels of GREB1 or TFF1 mRNAs were determined by RT-qPCR using ACTB mRNA as the normalizer. Data are represented as mean \pm SEM $(n=3)$; ${ }^{*} p<$ $0.05 ; * * p<0.01$; ***, $p<0.001$. g Dox-induced FLAG-tagged WT, Y537S, and D538G ER $\alpha$ proteins occupy EREs of GREB1 and TFF1 genes in MCF-7 cells, implying direct transcriptional regulation. In contrast, $\mathrm{ER} \alpha$ proteins minimally occupy a negative control region from intron 4 of the CCND1 gene, which lacks endogenous ER $\alpha$ binding [36]. Where indicated, WT ER $\alpha$ cells were treated with $100 \mathrm{nM}$ E2 for $45 \mathrm{~min}$. ChIP assays employed an antibody against FLAG to IP the FLAG-tagged ER $\alpha$ proteins and associated DNA. Isolated DNA was assayed by ChIP-qPCR. Representative data were plotted relative to percentage of starting input chromatin and are represented as mean of triplicate qPCR reactions \pm SEM. Supplementary Figure $7 d$ shows a repeated ChIP assay. h KMT2D occupies EREs of GREB1 and TFF1 genes in a Dox-dependent manner correlating with increased Y537S ER $\alpha$ occupancy. ChIP-qPCR was performed using an antibody to KMT2D. Representative data were plotted as above and the CCND1 gene intron 4 served as a negative control region. Supplementary Figure 7e shows a repeated ChIP assay

conditional (doxycycline (Dox)-inducible) expression of FLAG-tagged WT, Y537S, or D538G ER $\alpha$. The FLAG tag did not impair the transcriptional activities of ER $\alpha$ proteins (Supplementary Figure 6). Dox addition to cells grown in charcoal-stripped media induced expression of these ER $\alpha$ proteins, with Y537S and D538G ER $\alpha$ accumulating to a similar extent but less than WT (Fig. 5a). We next performed co-immunoprecipitations to test whether SRC-3 and KMT2D displayed enhanced association with inducible mutant ER $\alpha$ proteins under hormone-depleted conditions. We found greatest KMT2D and SRC-3 association with the Y537S mutant, with less recruited to D538G ER $\alpha$ (Fig. 5b). Importantly, the Dox-inducible mutant ER $\alpha$ proteins activated endogenous ER $\alpha$ target genes (GREBl and TFF1) in a hormone-independent manner and D538G ER $\alpha$ had a weaker effect than Y537S, in accordance with other models [7, 9, 29-31] (Fig. 5c and Supplementary Figure 7a). We next asked whether ablation of these key co-regulators would inhibit the viability of these cells. Consistently, SI-1 significantly reduced the viability of all ER $\alpha$-expressing cells (Fig. 5d), while knockdown of KMT2C/2D selectively affected WT and Y537S ER $\alpha$-expressing cells (Fig. 5e).

\section{Knockdown of KMT2C/2D modulates Y537S ERa direct target gene expression}

We next tested the effect of KMT2C/2D depletion on GREB1 and TFF1 gene expression in our Dox-inducible MCF-7 cells. KMT2C/2D knockdown reduced Y537S ER $\alpha$-mediated transcription of both genes (Fig. 5f and Supplementary Figure 7b). In WT ER $\alpha$ cells, the loss of KMT2C/2D also reduced TFF1 mRNA, but GREB1 or $E S R 1$ were unaffected. We extended our analysis to 10 total $\mathrm{ER} \alpha$ target genes by depleting only KMT2D using a validated siRNA [32], as KMT2D had greater recruitment than KMT2C to Y537S ER $\alpha$ (Fig. 1c). We observed that Y537S mutant expression regulates select ER $\alpha$ targets, a subset of which is reduced by KMT2D depletion (Supplementary Figure 7c).

Chromatin immunoprecipitation (ChIP) was used to examine whether the ER $\alpha$ mutants bound EREs [33-35] located upstream of the GREBI and TFF1 gene transcription start sites (TSS) in a Dox-dependent manner (Fig. 5g and Supplementary Figure 7d). All ER $\alpha$ proteins displayed Dox-dependent enrichment on EREs upstream of the GREB1 and TFF1 TSS, but not on a negative control region [36]. Thus, the binding of the LBD mutant ER $\alpha$ proteins to multiple EREs suggests direct regulatory roles in regulation of these genes.

\section{Chromatin occupancy of Y537S ERa and KMT2D are positively correlated}

As SRC-3 and p300 are co-localized with Y537S ER $\alpha$ on chromatin [29], we next tested whether KMT2D chromatin occupancy correlated with Y537S ER $\alpha$. We performed ChIP using a validated KMT2D antibody [37, 38] (Fig. 5h and Supplementary Figure 7e). KMT2D occupancy increased in Y537S ER $\alpha$ cells in a Dox-dependent manner for all EREs assayed, but not for the control region, without increased KMT2D protein expression (Supplementary Figure 7f). Thus, Dox-induced occupancy of EREs by Y537S 
a

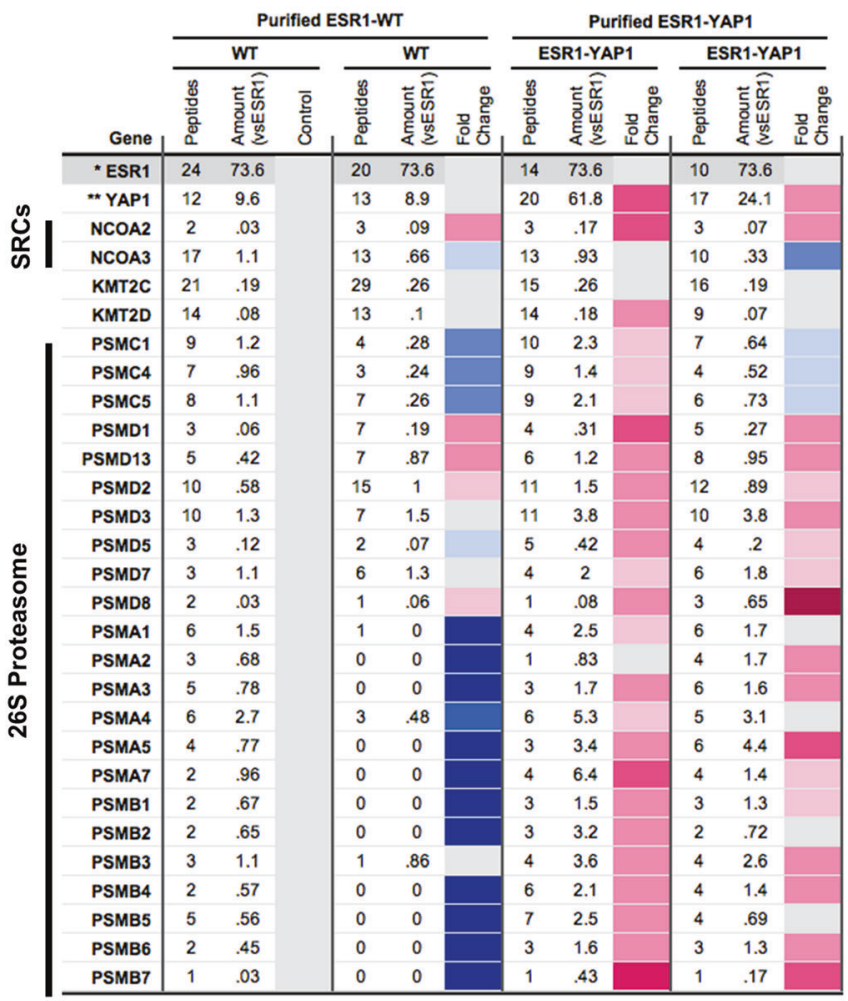

C

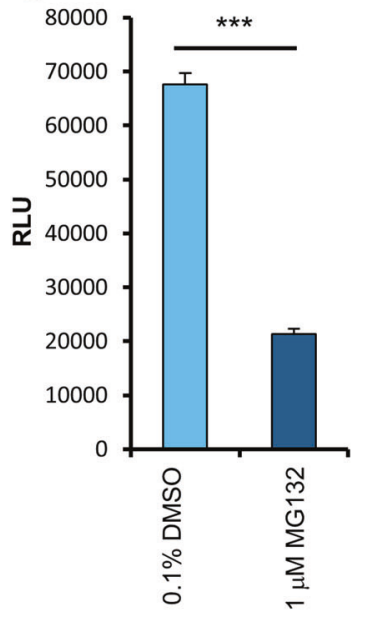

\section{b $1 / 3^{\text {rd }}$ of ERE beads}

(i)

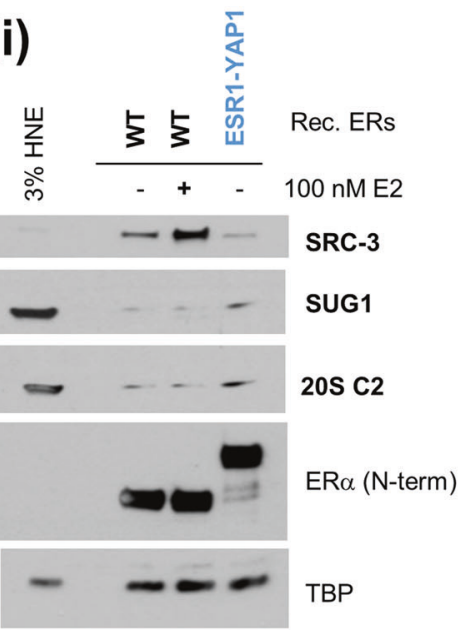

Fig. 6 The ESR1-YAP1 fusion protein recruits the 26S proteasome for activated transcription of an ERE-driven luciferase reporter. a MS data depicted as a heatmap (displayed as in Fig. 1c) for ESR1-YAP1dependent coactivators recruited to EREs from HNE. Recombinant purified WT or ESR1-YAP1 proteins were added to duplicate ERE DNA pulldown reactions. Fold change cutoff was $\geq 1.5$ for enrichment over unliganded WT ER $\alpha$. ${ }^{*} E S R 1$ normalized ESR1 (see Supplementary Table 2). **YAP1 YAP1 corrected for ESR1. b Immunoblotting validation of the 26S proteasome being recruited to ESR1YAP1. Independent ERE DNA pulldown samples were used to detect proteins recruited to ESR1-YAP1 compared to WT with/without E2 (i) or compared to WT or Y537S ER $\alpha$ (ii). Levels of ER $\alpha$ bound to the
EREs were determined with an ER $\alpha$ antibody recognizing an $\mathrm{N}$ terminal (N-term) epitope. TBP served as a loading control. 3\% HNE, $3 \%$ of the starting HeLa S3 NE employed in the ERE DNA pulldown. c A $26 \mathrm{~S}$ proteasome inhibitor, MG132, reduces ESR1-YAP1 transcriptional activity on an ERE-driven luciferase reporter. HeLa cells grown in phenol red-free, charcoal-stripped media were co-transfected with a vector expressing YFP-tagged ESR1-YAP1 protein and pEREE1b-luc. Cells were then treated with vehicle (0.1\% DMSO) or $1 \mu \mathrm{M}$ MG132 for overnight. Luciferase activity ( $R L U$ relative light units) was assayed from whole-cell lysates. Data are represented as mean \pm $\operatorname{SEM}(n=3) ; * * * p<0.001$ 


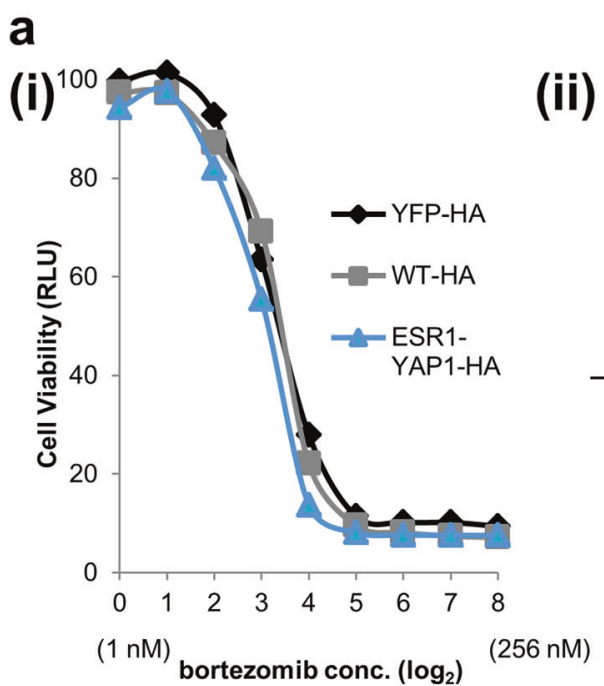

C TFF1 ERE3 $(-9.9 \mathrm{~kb})$
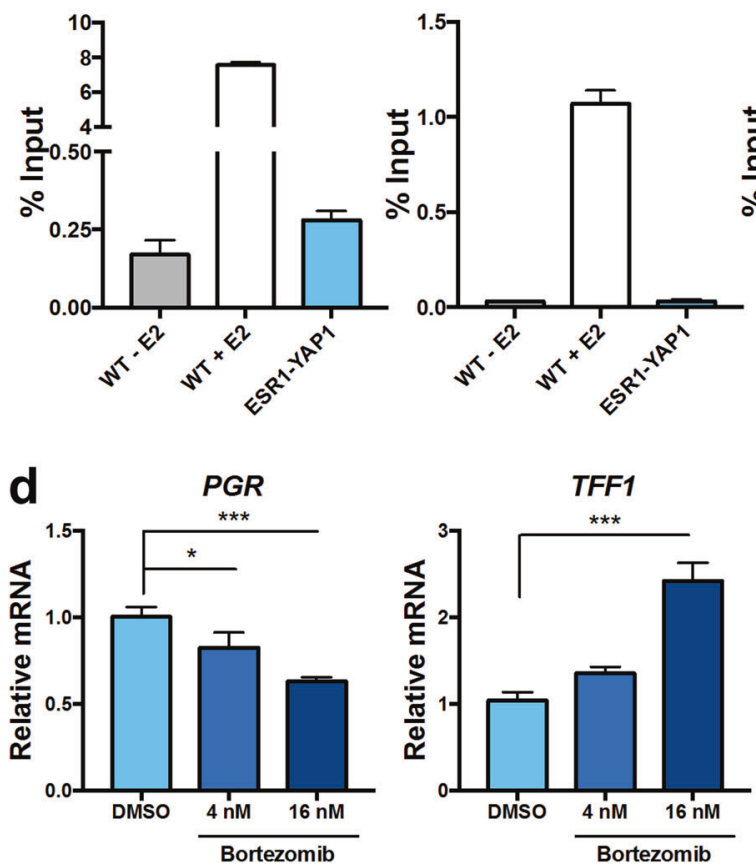

Fig. 7 Proteasome inhibition reduces viability of breast cancer cells expressing the ESR1-YAP1 fusion and modulates ESR1-YAP1 target gene expression. T47D cell lines expressing these constructs were grown in phenol red-free, charcoal-stripped media for at least 2 days. a Increasing concentrations of bortezomib reduce cell viability of HA epitope-tagged YFP, WT ER $\alpha$, and ESR1-YAP1 stably expressing T47D cell lines. (i) Cell viability was measured (via Cell Titer Glo as RLU) after 3 days of bortezomib or vehicle (DMSO) treatments. Data are represented as mean $\pm \operatorname{SEM}(n=3)$. (ii) Expression levels of ER $\alpha$ proteins were assayed in whole-cell extracts made from HA-tagged YFP, WT ER $\alpha$, and ESR1-YAP1 expressing T47D cell lines. The Nterminal ER $\alpha$ antibody was used to detect endogenous ER $\alpha$ (denoted by $\rightarrow$ ) as well as the ESR1-YAP1 fusion. $\beta$-actin served as a loading control. b Expression of HA-tagged ESR1-YAP1 activates expression of two classical ERE-containing target genes as compared to E2deprived HA-tagged WT ER $\alpha$. WT ER $\alpha$-expressing cells were treated with/without $10 \mathrm{nM} \mathrm{E2}$ for $24 \mathrm{~h}$. Relative levels of $T F F 1$ or $P G R$ b
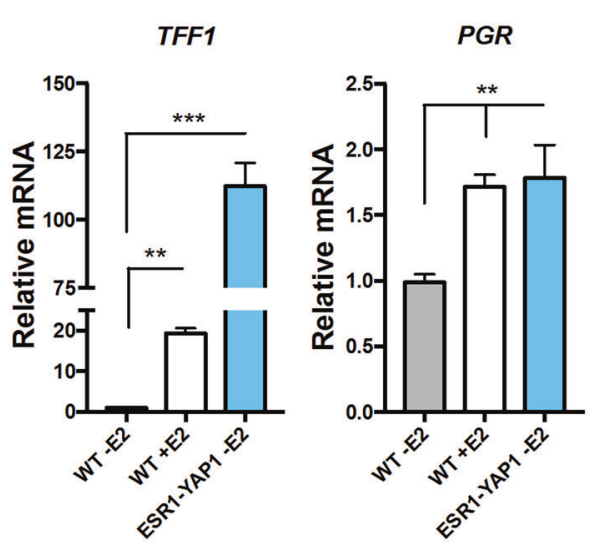

$\beta$-Actin

CCND1 Intron 4
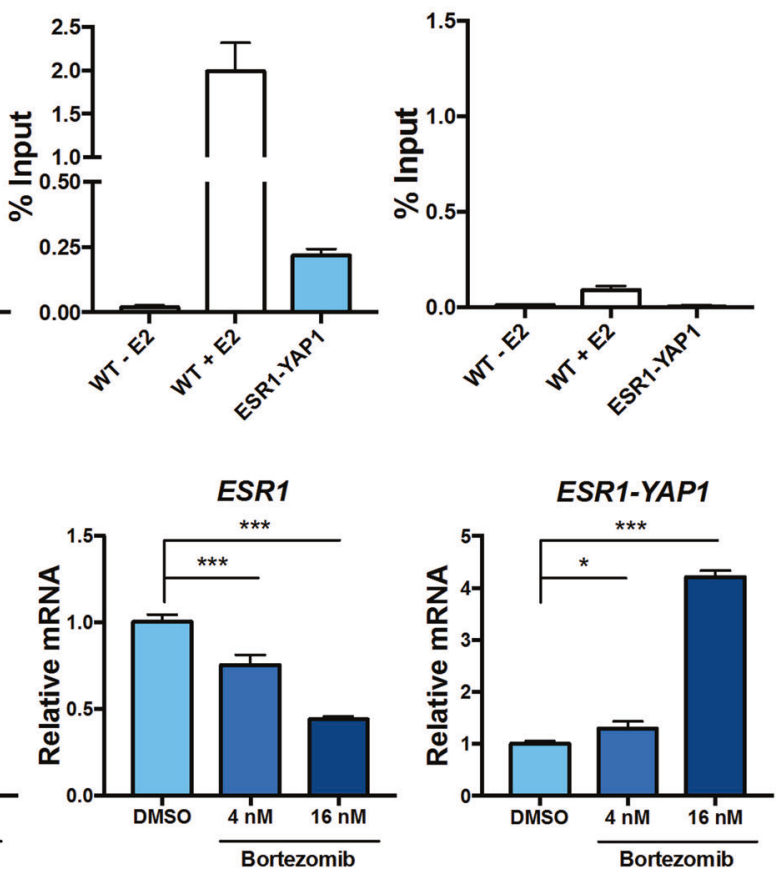

mRNAs were determined by RT-qPCR using $A C T B$ mRNA as the normalizer. Data are represented as mean $\pm \operatorname{SEM}(n=3)$; $* * p<0.01$; $* * * p<0.001$. c ESR1-YAP1 directly occupies certain EREs of the TFF1 and PGR genes. Where indicated, HA-tagged WT ER $\alpha$ cells were treated with $100 \mathrm{nM}$ E2 for $45 \mathrm{~min}$ before ChIP assays. ChIPqPCR assays employed an antibody against HA to IP the HA-tagged $\mathrm{ER} \alpha$ proteins and associated DNA. Representative data were plotted relative to percentage of starting input chromatin, which was represented as the mean of triplicate qPCR reactions \pm SEM. CCND1 gene intron 4 served as a negative control region. Supplementary Figure $8 \mathrm{~d}$ shows a repeated ChIP assay. d Proteasome inhibitor treatment of T47D cells expressing HA-tagged ESR1-YAP1 modulates EREcontaining target gene expression. Cells were treated with vehicle $(0.1 \%$ DMSO) or 4 or $16 \mathrm{nM}$ bortezomib for $17 \mathrm{~h}$. Relative levels of $P G R, T F F 1, E S R 1$, or ESR1-YAP1 mRNAs were determined by RTqPCR using GAPDH mRNA as the normalizer. Data are represented as mean $\pm \operatorname{SEM}(n=3) ; * p<0.05 ; * * * p<0.001$ 
ER $\alpha$ is correlated with increased recruitment of KMT2D and enhanced transcription of GREBI and TFF1.

\section{Co-regulators recruited to the ESR1-YAP1 fusion}

We next investigated co-regulator recruitment to ESR1YAP1, which contains the $\mathrm{N}$ terminus and DBD, but lacks the LBD, of ER $\alpha$ fused in-frame to the $\mathrm{C}$ terminus of the Yes-associated protein $1^{11}$ (Fig. 1a). ESR1-YAP1 promotes high levels of expression of an ERE-dependent reporter without E2 (Fig. 1b and Supplementary Figure 6a). We compared co-regulator recruitment to either purified WT ER $\alpha$ or ESR1-YAP1 bound to ERE DNA in the absence of E2 (Fig. 6a). After normalization for ER $\alpha$-binding differences, the ESR1-YAP1 protein did not recruit more SRC-3 and KMT2D as compared to WT ER $\alpha$, unlike the LBD ER $\alpha$ mutants (validated in Fig. 1d). Instead, the ESR1-YAP1 protein recruited many subunits of the $26 \mathrm{~S}$ proteasome (Fig. 6a). Immunoblotting validated enhanced proteasome recruitment (SUG1/PSMC5 and 20S C2/PSMA1) of ESR1YAP1 vs. WT ER $\alpha$, even with E2 (Fig. 6b). We further validated that the $26 \mathrm{~S}$ proteasome was recruited to ESR1YAP1 in E2-deprived T47D stable cell line [11] extracts (Supplementary Figure 8a).

The $26 \mathrm{~S}$ proteasome plays a role in WT ER $\alpha$ degradation that is linked with the receptor's ability to activate EREdriven reporter genes [39-41]. We thus tested whether a proteasome inhibitor, MG132, would similarly inhibit ESR1-YAP1 transcriptional activity. Indeed, MG132 treatment of cells transfected with an ERE-driven reporter and an ESR1-YAP1 expression plasmid reduced Luc activity, as compared to the vehicle control (Fig. 6c). Interestingly, MG132 or the FDA-approved proteasome inhibitor, bortezomib, could inhibit the transcriptional activity of a GAL4 DBD-YAP1 fusion (Supplementary Figure 8b).

\section{Proteasome activity is important for ESR1-YAP1- mediated cell growth and gene expression}

We next tested the functional significance of the ESR1YAP1: 26S proteasome interaction in T47D stable lines expressing HA-tagged YFP, WT ER $\alpha$, or ESR1-YAP1 proteins (Fig. 7aii and Supplementary Figure 8c). Increasing concentrations of bortezomib treatment for 3 days efficiently reduced the growth of all three T47D lines compared to the vehicle control (Fig. 7a,i).

We next wanted to define the effect of ESR1-YAP1 expression in T47D cells grown in an E2-deprived state on ER $\alpha$ target gene expression. The ESR1-YAP1 fusion promoted the expression of two target genes, TFF1 and PGR, significantly above the level of unliganded WT ER $\alpha$ expressing cells (Fig. 7b), even though much less ESR1YAP1 fusion was expressed (Fig. 7a, ii and Supplementary
Figure 8c). The regulation of these two genes is likely direct, as ChIP assays revealed ESR1-YAP1 occupancy at two defined ERE enhancer-like sequences [35, 42] (Fig. 7c and Supplementary Figure 8d).

The effect of proteasome inhibition on TFF1 and $P G R$ gene expression in E2-deprived ESR1-YAP1-expressing cells was tested by treating cells with bortezomib (Fig. 7d). Proteasome inhibition had both a dose-dependent and genespecific effect on the ESR1-YAP1 targets, decreasing PGR and increasing $T F F 1$, which resembles the effect of proteasome inhibitors on these genes after E2 treatment of MCF-7 cells [43-46]. Bortezomib decreased endogenous ESR1 mRNA expression, consistent with prior reports [43, 47]. Finally, we observed that bortezomib stimulated ESR1YAP1 mRNA expression (driven by the CMV promoter), which may explain why bortezomib did not severely reduce ESR1-YAP1 cell viability as compared to overexpressed WT ER $\alpha$ (Fig. 7a). Thus, the proteasome modulates ESR1YAP1 target genes and cell growth, suggesting a new approach for treating tumors bearing this class of resistance mutation.

\section{Potential clinical relevance of mutant ERa-binding coactivators}

To investigate whether the expression levels of the coactivators identified in this study correlate with patient outcomes, we queried two existing expression data sets-the Symmans Breast 2 ER-positive tamoxifen-treated patients [48] or ER-positive breast cancer patients treated with endocrine therapy (in KM plotter [49]; Supplementary Figure 9). In the Symmans data set, we found significantly higher KMT2D mRNA levels in patients who had a metastatic occurrence after 3 years of tamoxifen treatment vs. those that had not (panel a). We also found that higher SRC3 and proteasomal subunit mRNA levels correlated with reduced survival from distant metastasis (panels b, c). In the KM plotter analysis, we found that higher KMT2D, but not KMT2C, mRNA significantly correlated with reduced recurrence-free survival (panel d). Finally, we assayed a metastatic breast cancer mutation/amplification database [50] and found that the ESR1 LBD mutations were not present in patients with mutations in either KMT2C or KMT2D genes (panel e).

\section{DISCUSSION}

Different therapeutic approaches have been proposed to inhibit LBD mutant ER $\alpha$ proteins in breast cancers (Fig. 8) [23, 26, 27, 29-31, 51-54]. However, resistance to these therapies will occur. We envisioned that by defining the co- 
Fig. 8 Potential ways to inhibit mutant ER $\alpha$-driven breast cancer cell growth. In metastatic breast cancer, the ESRI gene encoding $\mathrm{ER} \alpha$ is mutated in exon 6 (by translocations creating in-frame fusion proteins such as ESR1YAP1) or in exon 8 (by point mutation in the LBD creating Y537S or D538G ER $\alpha$ mutants). While other laboratories have published pharmacological inhibitor strategies for reducing ESR1 mutant gene transcription (a), for inhibiting the LBD mutant $\mathrm{ER} \alpha$ proteins directly (b), and for inhibiting downstream gene products whose expression is driven by LBD mutant ER $\alpha$ proteins (d), we propose that inhibition of key mutant $\mathrm{ER} \alpha$ coactivators, such as KMT2C/2D, SRC coactivators, and the proteasome, is a new therapeutic approach for inhibiting mutant ER $\alpha$-driven breast cancer cell growth (c). See also Discussion

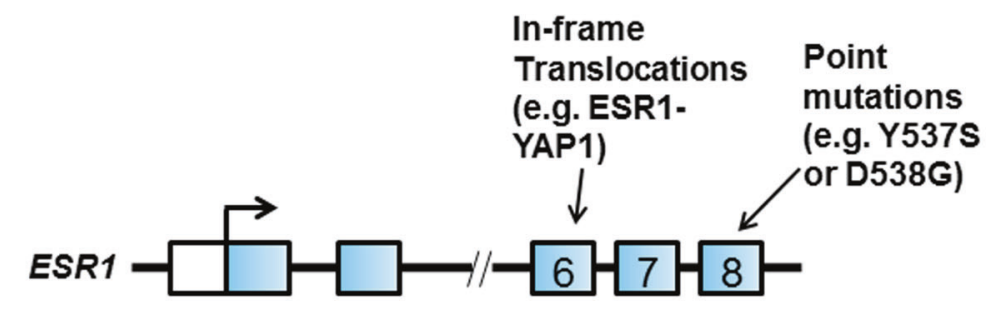

\section{A. "Upstream" inhibition of ESR1 gene transcription: BET Domain SMIs}

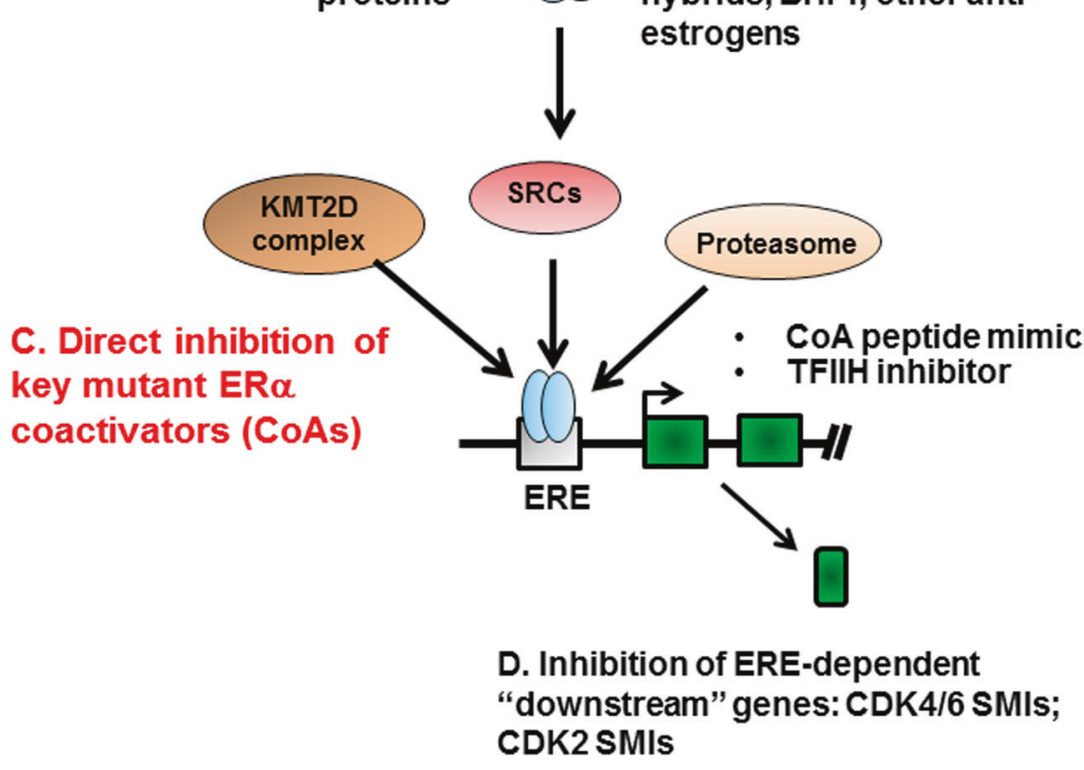

regulator "complexome" of each ESR1 mutant protein we could identify new potential therapeutic targets (Fig. 8c).

We identified coactivators that exhibit enhanced binding to $\mathrm{ER} \alpha$ mutant proteins. Consistent with prior literature [7, 9, 14, 18, 19, 55, 56], SRCs display enhanced recruitment to EREs bound by the two LBD $\mathrm{ER} \alpha$ mutants as compared with unliganded WT ER $\alpha$. Since all three SRCs are recruited to the two $\mathrm{LBD} \mathrm{ER} \alpha$ mutants, therapeutic intervention likely must be directed toward all three proteins. Accordingly, we show that a pan-SRC SMI can effectively inhibit LBD $\mathrm{ER} \alpha$ mutant activity and breast cancer cell growth (Fig. 2). Furthermore, combining pan-SRC SMI and oral SERD treatments have a synergistic effect on both LBD mutant transcriptional activity and cell growth (Fig. 2), and, more importantly, Y537S ER $\alpha$-expressing PDX tumor growth (Fig. 3).

Our results further reveal coactivator complexes preferentially interacting with $\operatorname{ER} \alpha$ mutants. First, we show that KMT2C/2D H3K4 methyltransferases are preferentially recruited to Y537S (Fig. 1c, Supplementary Figure 2a). These complexes were previously shown to coactivate E2- bound WT ER $\alpha$ in MCF-7 cells [57-60]. Although Y537S and D538G are one amino-acid residue apart in helix 12, it is striking that the $\mathrm{KMT} 2 \mathrm{C} / 2 \mathrm{D}$ complex is preferentially recruited to $\mathrm{Y} 537 \mathrm{~S}$, and that it promotes the growth of Y537S ER $\alpha$-expressing cells (Fig. 5e, Supplementary Figure 5). Detailed structural analysis is needed to examine how such coactivator-binding selectivity is achieved. As expression of $\mathrm{Y} 537 \mathrm{~S} \mathrm{ER} \alpha$ confers poor prognosis in metastatic breast cancer [16], our data suggest that developing targeted inhibitors of KMT2C/2D would be worthwhile for inhibition of Y537S $\mathrm{ER} \alpha$ mutant activity. Furthermore, KMT2D is oncogenic in ER-positive breast cancers resistant to $\mathrm{PI} 3 \mathrm{~K} \alpha$ inhibitors [61].

Second, we have profiled coactivators bound to ESR1YAP1, as it represents a "paradigmatic" gene fusion that activates ERE-driven transcription (Figs. 1b, 7b, Supplementary Figure 6). The ESR1-YAP1 fusion biochemically behaved in a distinct manner from the two LBD ER $\alpha$ mutants, as it displayed enhanced recruitment of the $26 \mathrm{~S}$ proteasome (Fig. 6, Supplementary Figure 8a). Furthermore, proteasome activity is important for both ESR1- 
YAP1 transcriptional activity and growth of breast cancer cells (Figs. 6c, 7a, b). As the proteasome inhibitor bortezomib is in clinical trial for $\mathrm{ER} \alpha$-positive, metastatic breast cancer (NCT01142401), we propose that it may reduce ESR1-YAP1-mediated tumor growth. Recently, other ESRl gene fusions [20] have been identified in ERpositive metastatic disease and whether they also utilize the proteasome for their activity should be further investigated.

In summary, our study utilized an MS approach profiling three different mutant $\mathrm{ER} \alpha$ proteins, which identified coactivators preferentially recruited to LBD mutants vs. an ESR1 gene fusion. We further showed that inhibition of these coactivators decreased ERE-driven transcription and reduced growth of breast cancer cells expressing these ER $\alpha$ mutants. Importantly, the combination of a panSRC inhibitor and oral SERD reduced the tumor growth of a human PDX expressing the Y537S ER $\alpha$ mutant, suggesting this as a potential new therapeutic strategy. We further identify additional potential therapeutic targets for Y537S ER $\alpha$-expressing breast cancers (KMT2C/ 2D complexes) and for the ESR1-YAP1 fusion (26S proteasome) for which no prior targets were known. Together, our data support the idea that differential coactivator recruitment may be partly responsible for the ability of $\mathrm{ER} \alpha$ mutant proteins to potentially drive metastatic breast cancer.

\section{Materials and methods}

\section{Cell lines}

Lines were obtained from BCM tissue culture core (originally from ATCC) unless otherwise indicated. STR profiling validated MCF-7 cell line authenticity. All lines tested negative for mycoplasma. MCF-7 and T47D cell lines stably expressing WT, Y537S, and D538G ER $\alpha$ were described [28]. C-terminal HA-tagged YFP, ESR1-WT, and ESR1-YAP1 lentiviral T47D cell lines were generated as in [11] using the pCD516B-2 vector (System Biosciences). Dox-inducible N-terminal FLAG-tagged WT, Y537S, and D538G ER $\alpha$ stable MCF-7 cell lines were constructed with pCW-FLAG-ER $\alpha$ lentiviruses. All lines were maintained in media containing $10 \%$ fetal bovine serum and switched to phenol red-free, hormone-depleted media before treatments.

\section{Plasmids}

pCW-FLAG-WT, Y537S, or D538G were created from pCW-Cas9 [62] (Addgene). pFLAG-CMV constructs were made from pFLAG-CMV2 (Sigma). YFP-tagged ESR1-
YAP1 was constructed by PCR of the ESR1-YAP1 open reading frame (ORF) [11], followed by ligation into digested pECFP-C1 (Clontech). pBIND-YAP1 (GAL4 DBD-YAP1 amino acid 230-504 fusion expression plasmid) was constructed by ligation into pBIND (Promega). All constructs were sequenced.

\section{ERE DNA pulldown assays}

The ERE DNA pulldown was described [21]. One microgram of purified receptor was added to 2-2.5 mg HNE and 15 pmol 4xERE-E4 DNA immobilized on Dynabeads M280 streptavidin (Invitrogen). For Supplementary Figure 8a, $\mathrm{NE}$ was made as described [63]. For direct interaction assays, $10 \mu \mathrm{l}$ of the purified recombinant KMT2D "fusion" complex [22] was incubated with $0.25 \mu \mathrm{g}$ of purified ER $\alpha$ for $1.5 \mathrm{~h}$ at $4{ }^{\circ} \mathrm{C}$ followed by washes and elution [21].

\section{Mass spectrometry}

MS was performed and analyzed as described [21]. All data sets are summarized in Supplementary Tables 1, 2, and 7. The raw MS proteomics data were deposited to the ProteomeXchange Consortium (http://proteomecentral. proteomexchange.org), data set identifier: PXD005887.

\section{Recombinant ERa proteins}

Flag-tagged ER $\alpha$ ORFs were expressed using the BaculoDirect N-terminal Expression kit (Invitrogen). Infected Sf9 cells were lysed in lysis buffer $(50 \mathrm{mM}$ Tris-Cl, $\mathrm{pH} 7.5$, $500 \mathrm{mM} \mathrm{NaCl}, 15 \%$ glycerol, $0.01 \% \mathrm{NP} 40,10 \mathrm{mM} \beta$-glycerophosphate and protease inhibitor cocktail (Roche)), followed by purification using anti-FLAG M2 antibodyconjugated beads and $3 \times$ FLAG peptide (Sigma).

\section{Co-immunoprecipitations}

Dox-treated MCF-7 cells expressing WT or LBD mutant $\mathrm{ER} \alpha$ proteins were lysed in NETN buffer [21]. Three milligrams whole-cell extract was incubated for $4 \mathrm{~h}$ at $4{ }^{\circ} \mathrm{C}$ with $5 \mu \mathrm{g}$ mouse anti-FLAG-pre-bound Protein G Dynabeads (Invitrogen) and washed with NETN and PBS.

\section{Reagents}

Dimethyl sulphoxide, 17ß-estradiol (E2), 4-hydroxytamoxifen, ICI182,780 (ICI), MG132, and Dox were purchased from Sigma. Bortezomib (Selleckchem), AZD9496 (MedChemExpress), and GDC0180 (Active Biochem) were from listed vendors. SI-1 and SI-2 have been described [25]. Antibodies are listed in Supplementary Table 3. 


\section{Luc reporter assays and siRNA transfections}

For ERE-Luc assays, HeLa cells were transfected with pERE-E1b-Luc [39] and ER $\alpha$ expression vector using Lipofectamine LTX (Invitrogen), and lysed in Glo Lysis Buffer (Promega). For GAL4-Luc assays, cells were transfected with pBIND-YAP1 and pG5luc (Promega). Luc activity was measured on a Berthold luminometer as described [64]. Cells were co-transfected with pERE-E1bluc, ER $\alpha$ expression plasmids, and siRNAs using Trans-ITTKO (Mirus Corp.) or RNAimax (Invitrogen). siRNAs are listed in Supplementary Table 3.

\section{Cell viability and soft agar assays}

Cell viability or soft agar anchorage-independent cell growth was measured after 3 days by either a CellTiterGlo $^{\circledast}$ Luminescent assay (Promega) or by a MTT assay [65].

\section{Chromatin immunoprecipitation}

Cells in hormone-depleted media were subject to ChIP assays performed using the EZ-ChIP kit (Millipore) as described [21]. See Supplementary Table 3.

\section{Calculations of synergism and $\mathrm{IC}_{50}$}

Synergism between two drugs was defined as a combination index $<1$ using CompuSyn (http://www.combosyn.com/) or Calcusyn (http://www.biosoft.com/w/calcusyn.htm) software [66]. $\mathrm{IC}_{50}$ values were determined by using Very Simple IC50 Tool Kit (http://www.ic50.tk/).

\section{Statistical analysis}

$P$ values were calculated using Student's $t$-test (two-sample, two-tailed) to compare two means or ANOVA (ordinary, one-way) followed by adjusting for multiple comparisons using the Dunnett or Tukey method. $P$ values $<0.05$ were considered significant. For statistics, experiments were performed with three to eight biological replicates (see figure legends).

\section{Real-time reverse transcription}

Total RNA was isolated with Direct-zol RNA MiniPrep (Zymo Research) or RNeasy (Qiagen) kits. cDNA synthesis and real-time reverse transcription (RT-qPCR) data analysis were carried out as described [64]. See Supplementary Table 3 for primers.

\section{PDX experiments}

Experiments were carried out in accordance with protocol AN-1875 approved by the BCM Institutional Animal Care and Use Committee. WHIM 20 PDX was transplanted as described [11] into 4-5-week-old female SCID/Beige mice (Envigo). Mice were palpated semi-weekly, and tumor growth measured using calipers. When tumors reached $\sim 350 \mathrm{~mm}^{3}$ (volume $\left.=L \times((W \times W) / 2)\right)$, the mice were randomized into four treatment groups $(n=10$ each): (1) AZD9496 5 days/week by oral gavage once daily, $5 \mathrm{mg} / \mathrm{kg}$ body weight (b.w.) [14, 26]; (2) SI-2 twice daily 5 days/ week by intraperitoneal (i.p.) injection at $2 \mathrm{mg} / \mathrm{kg}$ b.w. [25]; (3) combination of both inhibitors as described; and (4) control PBS vehicle (oral and i.p.). Mice were sacrificed and tissues harvested at 4 months post transplantation. Tumor volume of eight mice per group (which completed at least 4.5 weeks of treatment) was analyzed. Representative tumors ( $n=6 /$ treatment) were lysed in RIPA buffer with phosphatase and protease inhibitors (Calbiochem). Hematoxylin and eosin staining and immunohistochemistry were performed by the Lester and Sue Smith Breast Center Pathology Core at BCM. After staining, images were captured on an OLYMPUS DP73 microscope. For BrdU analysis, $7 \mathrm{mg} / \mathrm{ml} \mathrm{BrdU} \mathrm{(Sigma)} \mathrm{was} \mathrm{prepared} \mathrm{in} \mathrm{PBS} \mathrm{and} \mathrm{i.p.}$ injected at $10 \mu \mathrm{l} / \mathrm{g}$ b.w. After $2 \mathrm{~h}$, the mice were sacrificed $(n=8)$. Slides were stained by BD Pharmingen in SituDetection KIT II and were visualized with diaminobenzidine tetrahydrochloride (Dako), and counterstained with Harris hematoxylin. Images were analyzed in Matlab by the Integrated Microscopy Core at BCM. The investigators were not blinded to allocation during experiments and outcome assessment. No statistical methods were used to predetermine sample size estimate.

\section{Patient data analysis}

Oncomine was used to query the Symmans Breast 2 data set. KM plotter (kmplot.com) was used to query the ERpositive patients treated with endocrine therapy. See Supplementary Figure 9 for more details.

Acknowledgements We thank the following BCM cores (Tissue Culture, Monoclonal Antibody/Recombinant Protein and Mass Spectrometry Proteomics (funded by NCI P30 CA125123 and CPRIT RP170005), Gene Vector, Integrated Microscopy (funded by NIH (DK56338 and CA125123) and CPRIT (RP150578))), David Bader, Doug Chan, and Rainer Lanz. We acknowledge the joint participation with the Adrienne Helis Malvin Medical Research Foundation through its direct engagement in the continuous active conduct of medical research in conjunction with BCM and the Cancer Program. This work was supported by the NIH ((R01 HD008188 and R01 HD007857 to B. W.O.), (R01 CA207270 and R01 CA072038 to S.A.W.F), (R01 GM115622, R01 CA207701, and R21 CA213535 to J.W.), (R01 DK071900 and R01 CA178765 to R.G.R.), (1F31CA210385-01 to L. 
A.G.), and (T32 GM088129 to J.T.L.)), CPRIT ((RR140033 to M.J.E), (RP150440 and RP120732-P2 to S.A.W.F.), and (RP110784 to J.Q.)), Susan G. Komen Foundation ((PG12220321 to M.J.E.) and (CCR14300139 to Jieya Shao)), Breast Cancer Research Foundation (17-055 to S.A.W.F.), DOD ((W81XWH-13-1-0285 to B.W.O.) and (W81XWH-16-1-0539 to M.J.E.)), the Human Frontier Science Program Fellowship (LT000538/2011-L to S.P.W.), and the McNair Medical Foundation (M.J.E.).

\section{Compliance with ethical standards}

Conflict of interest B.W.O., D.M.L., J.W., A.D.R., Y.Y., and C.E.F. disclose an equity position in Coactigon, Inc.; M.J.E. received a consulting fee from AstraZeneca.

Open Access This article is licensed under a Creative Commons Attribution 4.0 International License, which permits use, sharing, adaptation, distribution and reproduction in any medium or format, as long as you give appropriate credit to the original author(s) and the source, provide a link to the Creative Commons license, and indicate if changes were made. The images or other third party material in this article are included in the article's Creative Commons license, unless indicated otherwise in a credit line to the material. If material is not included in the article's Creative Commons license and your intended use is not permitted by statutory regulation or exceeds the permitted use, you will need to obtain permission directly from the copyright holder. To view a copy of this license, visit http://creativecommons. org/licenses/by/4.0/.

\section{References}

1. Osborne CK, Schiff R. Mechanisms of endocrine resistance in breast cancer. Annu Rev Med. 2011;62:233-47.

2. Massarweh S, Schiff R. Unraveling the mechanisms of endocrine resistance in breast cancer: new therapeutic opportunities. Clin Cancer Res. 2007;13:1950-4.

3. Van Asten K, Neven P, Lintermans A, Wildiers H, Paridaens R. Aromatase inhibitors in the breast cancer clinic: focus on exemestane. Endocr Relat Cancer. 2014;21:R31-49.

4. Ciruelos E, Pascual T, Arroyo Vozmediano ML, Blanco M, Manso L, Parrilla L, et al. The therapeutic role of fulvestrant in the management of patients with hormone receptor-positive breast cancer. Breast. 2014;23:201-8.

5. Johnson AB, O'Malley BW. Steroid receptor coactivators 1, 2, and 3: Critical regulators of nuclear receptor activity and steroid receptor modulator (SRM)-based cancer therapy. Mol Cell Endocrinol. 2011;348:430-9.

6. Zhang QX, Borg A, Wolf DM, Oesterreich S, Fuqua SA. An estrogen receptor mutant with strong hormone-independent activity from a metastatic breast cancer. Cancer Res. 1997;57:1244-9.

7. Toy W, Shen Y, Won H, Green B, Sakr RA, Will M, et al. ESR1 ligand-binding domain mutations in hormone-resistant breast cancer. Nat Genet. 2013;45:1439-45.

8. Robinson DR, Wu YM, Vats P, Su F, Lonigro RJ, Cao X, et al. Activating ESR1 mutations in hormone-resistant metastatic breast cancer. Nat Genet. 2013;45:1446-51.

9. Merenbakh-Lamin K, Ben-Baruch N, Yeheskel A, Dvir A, Soussan-Gutman L, Jeselsohn R, et al. D538G mutation in estrogen receptor-alpha: a novel mechanism for acquired endocrine resistance in breast cancer. Cancer Res. 2013;73:6856-64.

10. Jeselsohn R, Yelensky R, Buchwalter G, Frampton G, MericBernstam F, Gonzalez-Angulo AM, et al. Emergence of constitutively active estrogen receptor-alpha mutations in pretreated advanced estrogen receptor-positive breast cancer. Clin Cancer Res. 2014;20:1757-67.

11. Li S, Shen D, Shao J, Crowder R, Liu W, Prat A, et al. Endocrinetherapy-resistant ESR1 variants revealed by genomic characterization of breast-cancer-derived xenografts. Cell Rep. 2013;4:1116-30.

12. Fribbens C, O'Leary B, Kilburn L, Hrebien S, Garcia-Murillas I, Beaney M, et al. Plasma ESR1 Mutations and the Treatment of Estrogen Receptor-Positive Advanced Breast Cancer. J Clin Oncol. 2016;34:2961-8.

13. Spoerke JM, Gendreau S, Walter K, Qiu J, Wilson TR, Savage H, et al. Heterogeneity and clinical significance of ESR1 mutations in ER-positive metastatic breast cancer patients receiving fulvestrant. Nat Commun. 2016;7:11579.

14. Toy W, Weir H, Razavi P, Lawson M, Goeppert AU, Mazzola $\mathrm{AM}$, et al. Activating ESR1 mutations differentially impact the efficacy of ER antagonists. Cancer Discov. 2016;7:277-87.

15. Schiavon G, Hrebien S, Garcia-Murillas I, Cutts RJ, Pearson A, Tarazona N, et al. Analysis of ESR1 mutation in circulating tumor DNA demonstrates evolution during therapy for metastatic breast cancer. Sci Transl Med. 2015;7:313ra182.

16. Chandarlapaty S, Chen D, He W, Sung P, Samoila A, You D, et al. Prevalence of ESR1 mutations in cell-free DNA and outcomes in metastatic breast cancer: a secondary analysis of the BOLERO-2 clinical trial. JAMA Oncol. 2016;2:1310-5.

17. Clatot F, Perdrix A, Augusto L, Beaussire L, Delacour J, Calbrix $\mathrm{C}$, et al. Kinetics, prognostic and predictive values of ESR1 circulating mutations in metastatic breast cancer patients progressing on aromatase inhibitor. Oncotarget. 2016;7:74448-59.

18. Lazennec G, Ediger TR, Petz LN, Nardulli AM, Katzenellenbogen BS. Mechanistic aspects of estrogen receptor activation probed with constitutively active estrogen receptors: correlations with DNA and coregulator interactions and receptor conformational changes. Mol Endocrinol. 1997;11:1375-86.

19. Fanning SW, Mayne CG, Dharmarajan V, Carlson KE, Martin TA, Novick SJ, et al. Estrogen receptor alpha somatic mutations Y537S and D538G confer breast cancer endocrine resistance by stabilizing the activating function-2 binding conformation. eLife. 2016;5:e12792.

20. Hartmaier RJ, Trabucco SE, Priedigkeit N, Chung JH, Parachoniak CA, Vanden Borre P, et al. Recurrent hyperactive ESR1 fusion proteins in endocrine therapy resistant breast cancer. Ann Oncol. 2018;29:872-80.

21. Foulds CE, Feng Q, Ding C, Bailey S, Hunsaker TL, Malovannaya A, et al. Proteomic analysis of coregulators bound to ERalpha on DNA and nucleosomes reveals coregulator dynamics. Mol Cell. 2013;51:185-99.

22. Wang SP, Tang Z, Chen CW, Shimada M, Koche RP, Wang LH, et al. A UTX-MLL4-p300 transcriptional regulatory network coordinately shapes active enhancer landscapes for eliciting transcription. Mol Cell. 2017;67:308-21e6.

23. Raj GV,Sareddy GR,Ma S,Lee TK,Viswanadhapalli S,Li R, et al. Estrogen receptor coregulator binding modulators (ERXs) effectively target estrogen receptor positive human breast cancers. eLife. 2017;6:e26857

24. Long W, Foulds CE, Qin J, Liu J, Ding C, Lonard DM, et al. ERK3 signals through SRC-3 coactivator to promote human lung cancer cell invasion. J Clin Invest. 2012;122:1869-80.

25. Song X, Chen J, Zhao M, Zhang C, Yu Y, Lonard DM, et al. Development of potent small-molecule inhibitors to drug the undruggable steroid receptor coactivator-3. Proc Natl Acad Sci USA. 2016;113:4970-5.

26. Weir HM, Bradbury RH, Lawson M, Rabow AA, Buttar D, Callis RJ, et al. AZD9496: an oral estrogen receptor inhibitor that blocks the growth of ER-positive and ESR1-mutant breast tumors in preclinical models. Cancer Res. 2016;76:3307-18. 
27. Joseph JD, Darimont B, Zhou W, Arrazate A, Young A, Ingalla E, et al. The selective estrogen receptor downregulator GDC-0810 is efficacious in diverse models of $\mathrm{ER}+$ breast cancer. eLife. 2016;5:e15828.

28. Gelsomino L, Gu G, Rechoum Y, Beyer AR, Pejerrey SM, Tsimelzon A, et al. ESR1 mutations affect anti-proliferative responses to tamoxifen through enhanced cross-talk with IGF signaling. Breast Cancer Res Treat. 2016;157:253-65.

29. Harrod A, Fulton J, Nguyen VT, Periyasamy M, Ramos-Garcia L, Lai CF, et al. Genomic modelling of the ESR1 Y537S mutation for evaluating function and new therapeutic approaches for metastatic breast cancer. Oncogene. 2016. https://doi.org/10.1038/ onc. 2016.382

30. Mao C, Livezey M, Kim JE, Shapiro DJ. Antiestrogen resistant cell lines expressing estrogen receptor alpha mutations upregulate the unfolded protein response and are killed by BHPI. Sci Rep. 2016;6:34753.

31. Jeselsohn R, Bergholz JS, Pun M, Cornwell M, Liu W, Nardone A, et al. Allele-specific chromatin recruitment and therapeutic vulnerabilities of ESR1 activating mutations. Cancer Cell. 2018;33:173-86e5.

32. Dawkins JB, Wang J, Maniati E, Heward JA, Koniali L, Kocher $\mathrm{HM}$, et al. Reduced expression of histone methyltransferases KMT2C and KMT2D correlates with improved outcome in pancreatic ductal adenocarcinoma. Cancer Res. 2016;76:4861-71.

33. Metivier R, Penot G, Hubner MR, Reid G, Brand H, Kos M, et al. Estrogen receptor-alpha directs ordered, cyclical, and combinatorial recruitment of cofactors on a natural target promoter. Cell. 2003;115:751-63.

34. Carroll JS, Meyer CA, Song J, Li W, Geistlinger TR, Eeckhoute J, et al. Genome-wide analysis of estrogen receptor binding sites. Nat Genet. 2006;38:1289-97.

35. Won Jeong K, Chodankar R, Purcell DJ, Bittencourt D, Stallcup MR. Gene-specific patterns of coregulator requirements by estrogen receptor-alpha in breast cancer cells. Mol Endocrinol. 2012;26:955-66.

36. Eeckhoute J, Carroll JS, Geistlinger TR, Torres-Arzayus MI, Brown M. A cell-type-specific transcriptional network required for estrogen regulation of cyclin D1 and cell cycle progression in breast cancer. Genes Dev. 2006;20:2513-26.

37. Bossi D, Cicalese A, Dellino GI, Luzi L, Riva L, D’Alesio C, et al. In vivo genetic screens of patient-derived tumors revealed unexpected frailty of the transformed phenotype. Cancer Discov. 2016;6:650-63.

38. Zhang J, Dominguez-Sola D, Hussein S, Lee JE, Holmes AB, Bansal M, et al. Disruption of KMT2D perturbs germinal center B cell development and promotes lymphomagenesis. Nat Med. 2015;21:1190-8.

39. Lonard DM, Nawaz Z, Smith CL, O'Malley BW. The 26S proteasome is required for estrogen receptor-alpha and coactivator turnover and for efficient estrogen receptor-alpha transactivation. Mol Cell. 2000;5:939-48.

40. Stenoien DL, Patel K, Mancini MG, Dutertre M, Smith CL, O'Malley BW, et al. FRAP reveals that mobility of oestrogen receptor-alpha is ligand- and proteasome-dependent. Nat Cell Biol. 2001;3:15-23.

41. Reid G, Hubner MR, Metivier R, Brand H, Denger S, Manu D, et al. Cyclic, proteasome-mediated turnover of unliganded and liganded ERalpha on responsive promoters is an integral feature of estrogen signaling. Mol Cell. 2003;11:695-707.

42. Boney-Montoya J, Ziegler YS, Curtis CD, Montoya JA, Nardulli AM. Long-range transcriptional control of progesterone receptor gene expression. Mol Endocrinol. 2010;24:346-58.

43. Powers GL, Ellison-Zelski SJ, Casa AJ, Lee AV, Alarid ET. Proteasome inhibition represses ERalpha gene expression in ER
+ cells: a new link between proteasome activity and estrogen signaling in breast cancer. Oncogene. 2010;29:1509-18.

44. Fan M, Nakshatri H, Nephew KP. Inhibiting proteasomal proteolysis sustains estrogen receptor-alpha activation. Mol Endocrinol. 2004;18:2603-15.

45. Kinyamu HK, Collins JB, Grissom SF, Hebbar PB, Archer TK. Genome wide transcriptional profiling in breast cancer cells reveals distinct changes in hormone receptor target genes and chromatin modifying enzymes after proteasome inhibition. Mol Carcinog. 2008;47:845-85.

46. Prenzel T, Begus-Nahrmann Y, Kramer F, Hennion M, Hsu C, Gorsler T, et al. Estrogen-dependent gene transcription in human breast cancer cells relies upon proteasome-dependent monoubiquitination of histone H2B. Cancer Res. 2011;71:5739-53.

47. Thaler S, Thiede G, Hengstler JG, Schad A, Schmidt M, Sleeman JP. The proteasome inhibitor Bortezomib (Velcade) as potential inhibitor of estrogen receptor-positive breast cancer. Int J Cancer. 2015;137:686-97.

48. Symmans WF, Hatzis C, Sotiriou C, Andre F, Peintinger F, Regitnig $\mathrm{P}$, et al. Genomic index of sensitivity to endocrine therapy for breast cancer. J Clin Oncol. 2010;28:4111-9.

49. Gyorffy B, Lanczky A, Eklund AC, Denkert C, Budczies J, Li Q, et al. An online survival analysis tool to rapidly assess the effect of 22,277 genes on breast cancer prognosis using microarray data of 1,809 patients. Breast Cancer Res Treat. 2010;123:725-31.

50. Robinson DR, Wu YM, Lonigro RJ, Vats P, Cobain E, Everett J, et al. Integrative clinical genomics of metastatic cancer. Nature. 2017;548:297-303.

51. Alluri PG, Larios J, Malik R, Rae J, Chinnaiyan AM. Targeting estrogen receptor mutations for treatment of endocrine therapy resistance in breast cancer. In: Proceedings of the 107th Annual Meeting of the American Association for Cancer Research; 16-20 April 2016; New Orleans, LA. Philadelphia, USA: AACR; Cancer Res. 2016;76:Abstract nr 2156.

52. Wardell SE, Ellis MJ, Alley HM, Eisele K, VanArsdale T, Dann SG, et al. Efficacy of SERD/SERM Hybrid-CDK4/6 inhibitor combinations in models of endocrine therapy resistant breast cancer. Clin Cancer Res. 2015;21:5121-30.

53. Zhao Y, Laws MJ, Guillen VS, Ziegler Y, Min J, Sharma A, et al. Structurally novel antiestrogens elicit differential responses from constitutively active mutant estrogen receptors in breast cancer cells and tumors. Cancer Res. 2017;77:5602-13.

54. Scott GK, Chu D, Kaur R, Malato J, Rothschild DE, Frazier K et al. ERpS294 is a biomarker of ligand or mutational ERalpha activation and a breast cancer target for CDK2 inhibition. Oncotarget. 2016; https://doi.org/10.18632/oncotarget.12735.

55. Weis KE, Ekena K, Thomas JA, Lazennec G, Katzenellenbogen BS. Constitutively active human estrogen receptors containing amino acid substitutions for tyrosine 537 in the receptor protein. Mol Endocrinol. 1996;10:1388-98.

56. Lake MC, Nguyen QD, Ali S, Aboagye EO. Development of a novel molecular sensor for imaging estrogen receptor-coactivator protein-protein interactions. PLoS ONE. 2012;7:e44160.

57. Jozwik KM, Chernukhin I, Serandour AA, Nagarajan S, Carroll JS. FOXA1 directs H3K4 monomethylation at enhancers via recruitment of the methyltransferase MLL3. Cell Rep. 2016;17:2715-23.

58. Wierer M, Verde G, Pisano P, Molina H, Font-Mateu J, Di Croce $\mathrm{L}$, et al. PLK1 signaling in breast cancer cells cooperates with estrogen receptor-dependent gene transcription. Cell Rep. 2013;3:2021-32.

59. Shi L, Sun L, Li Q, Liang J, Yu W, Yi X, et al. Histone demethylase JMJD2B coordinates H3K4/H3K9 methylation and promotes hormonally responsive breast carcinogenesis. Proc Natl Acad Sci USA. 2011;108:7541-6. 
60. Mo R, Rao SM, Zhu YJ. Identification of the MLL2 complex as a coactivator for estrogen receptor alpha. J Biol Chem. 2006;281:15714-20.

61. Toska E, Osmanbeyoglu HU, Castel P, Chan C, Hendrickson RC, Elkabets $\mathrm{M}$, et al. PI3K pathway regulates ER-dependent transcription in breast cancer through the epigenetic regulator KMT2D. Science. 2017;355:1324-30. Epub 2017/03/25

62. Wang T, Wei JJ, Sabatini DM, Lander ES. Genetic screens in human cells using the CRISPR-Cas9 system. Science. 2014;343:80-4.

63. Abmayr SM, Yao T, Parmely T, Workman JL. Preparation of nuclear and cytoplasmic extracts from mammalian cells. Current protocols in molecular biology. 2006;75:12.1.1-12.1.10.
64. Foulds CE, Tsimelzon A, Long W, Le A, Tsai SY, Tsai MJ, et al. Research resource: expression profiling reveals unexpected targets and functions of the human steroid receptor RNA activator (SRA) gene. Mol Endocrinol. 2010;24:1090-105.

65. Gu G, Gelsomino L, Covington KR, Beyer AR, Wang J, Rechoum Y, et al. Targeting thyroid hormone receptor beta in triple-negative breast cancer. Breast Cancer Res Treat. 2015;150:535-45.

66. Chou TC. Theoretical basis, experimental design, and computerized simulation of synergism and antagonism in drug combination studies. Pharmacol Rev. 2006;58:621-81. 